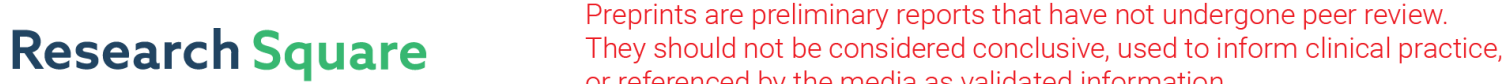 \\ or referenced by the media as validated information. \\ Using Fuzzy Control for Feedrate Scheduling of Computer Numerical Control Machine Tools
}

Cheng-Jian Lin ( $\nabla$ cjlin@ncut.edu.tw )

National Chin-Yi University of Technology

Chun-Hui Lin

National Cheng Kung University

Shyh-Hau Wang

National Cheng Kung University

\section{Research Article}

Keywords: Feedrate scheduling, fuzzy control, fuzzy rule, computer-aided manufacturing, machine tools

Posted Date: February 18th, 2021

DOI: https://doi.org/10.21203/rs.3.rs-203034/v1

License: (1) This work is licensed under a Creative Commons Attribution 4.0 International License.

Read Full License 


\title{
Using Fuzzy Control for Feedrate Scheduling of Computer Numerical Control Machine Tools
}

\author{
Cheng-Jian Lin ${ }^{1,2 *}$, Chun-Hui Lin ${ }^{3}$, and Shyh-Hau Wang ${ }^{3,4}$ \\ ${ }^{1}$ Department of Computer Science and Information Engineering, National Chin-Yi University of \\ Technology, Taichung 411, Taiwan \\ ${ }^{2}$ College of Intelligence, National Taichung University of Science and Technology, Taichung 404, Taiwan \\ ${ }^{3}$ Department of Computer Science and Information Engineering, National Cheng Kung University, \\ Tainan 701, Taiwan \\ ${ }^{4}$ Intelligent Manufacturing Research Center, National Cheng Kung University, Tainan 701, Taiwan \\ ${ }^{*}$ Correspondence: cjlin@ncut.edu.tw
}

\begin{abstract}
In industrial processing, workpiece quality and processing time have become important issues lately. Fortunately, dynamic cutting feedrate scheduling has been proposed to improve machining accuracy and decrease cutting time. Studies have shown that the curvature and cutting feedrate significantly influence the machining accuracy. Therefore, the present study proposes a fuzzy control system for feedrate scheduling based on the curvature and curvature variation. The proposed system is implemented in actual cutting, and an optical three-dimensional scanner is performed as a verification to measure the cutting trajectory of the workpiece. Experimental results prove that the proposed fuzzy control system for dynamic cutting feedrate scheduling increases the cutting accuracy by $43 \%$ under the same cutting time; moreover, it decreases the cutting time by $49 \%$ under the same cutting accuracy.
\end{abstract}

Keywords: Feedrate scheduling, fuzzy control, fuzzy rule, computer-aided manufacturing, machine tools

\section{Introduction}

Computer numerical control (CNC) machining is a manufacturing process automatically controlling the machine tools for producing high-precision workpieces. To achieve high-speed and high-precision machining, on-site operators typically adjust the feedrate in computer-aided manufacturing (CAM) software based on their experiences derived from previous cutting experiments. Previous studies have presented many advanced control methods such as optimal control and adaptive control of cutting conditions in order to improve machining accuracy [1-3]. Among them, 
dynamic feedrate scheduling uses two indicators for evaluating the feedrate: constant cutting force-based and processing path-based dynamic feedrate scheduling.

Firstly, in constant cutting force-based dynamic feedrate scheduling, the cutting force model is usually established depending on the cutting tool and the direction of the cutting velocity vector. In other words, the model provides a suitable feedrate instantly under a constant cutting force and spindle speed. Wang et al. [4] presented a feedrate optimization method for constant peak cutting force in the five-axis flank milling process to resolve the unstable machining of parts with ruled surfaces in the aviation industry. The optimization method used least squares theory with the cutter entry angle and feedrate as variables for establishing the peak cutting force for each cutting point. Moreover, a feedrate scheduling method was also designed to quickly solve the appropriate feedrate under constant peak cutting force. Kim et al. [5] proposed a mechanistic cutting force model to perform effective feedrate scheduling for indexable end milling in process planning. The developed cutting force model applied cuttingcondition-independent cutting force coefficients which took run out, cutter deflection, geometry variation and size effect as consideration for accurate cutting force prediction. Lee and Cho [6] developed a reference cutting force model based on considering the transverse rupture strength of the tool material and the area of the rupture surface. The experimental results revealed that the model provides an effective criterion for a feedrate scheduling system that regulates cutting force at a given criterion. All these studies have implemented a cutting force model to adjust the feedrate; however, feedrate scheduling is still associated with many difficulties, such as incompatibility of the cutting force model, sensors installation, and time-consuming experiments for establishing and verification the cutting force model.

Secondly, the poor processing quality such as large surface roughness and insufficient contour precision is mainly attributed to an incorrect processing feedrate or large jerk produced by excessive acceleration and deceleration. These situations likely occur when machining with a larger curvature thereby producing the chord errors [78]. Luan et al. [9] noted that the chord error was affected by the interpolation algorithm, curvature, and feedrate. In a condition of the same feedrate, an area with larger curvature produces a larger chord error, because the interpolation algorithm in most of the controller is constant, the feedrate must be reduced to maintain the chord error within the requirements; therefore, an offline dynamic feedrate scheduling method was proposed to alleviate the above mentioned problem. Yeh and Hsu [10] found that due to the non-uniform map between curves and parameters, it is very difficult to maintain a constant feedrate and chord accuracy between two interpolated points along parametric curves; therefore, an adaptive feedrate calculation using speed-controlled interpolation algorithm was proposed. Both simulation and experimental results for 
non-uniform rational B-spline (NURBS) examples were verified for the feasibility and precision of the proposed interpolation algorithm. Giannelli et al. [11] proposed a configurable trajectory planning strategy which can be applied to any planar path with a piecewise sufficiently smooth parametric representation. The processing path-based dynamic feedrate scheduling does not need to install an extra sensor. The establishment of a cutting force model does not require cutting experiments; therefore, employing the processing path-based dynamic feedrate scheduling is better than the other method in terms of practicality and versatility. Thus, the present study primary focuses on processing path-based dynamic feedrate scheduling method. An extended cutting experiment is needed to establish and verify the cutting force model. Therefore, this study uses fuzzy theory to control the dynamic cutting feedrate of a machine tool under the same processing software, cutting tool, and processing material to replace manual feedrate adjustment and improve the machining accuracy while shortening the processing time.

Fuzzy control was first proposed by L. A. Zadeh in 1964 [12], to develop a versatile control system and to avoid some of the difficulties associated with forcebased controllers, it has been widely used in various fields, such as signal processing, servo control, and image processing. The advantages of fuzzy controller are that it is suitable for nonlinear systems and that it is described by control laws made by experts in their field. Miao and Li [13] developed a fuzzy control system based on the assumed feed rate, radial and axial depths of cut for CNC profile milling feed rate determination to predict the cutting force. Liang et al. [14] established a fuzzy logic-based torque control system for optimizing the material removal rate in high-speed milling processes. The aforementioned studies have all used fuzzy controllers to achieve good results; therefore, this study uses fuzzy control in processing path-based dynamic feedrate scheduling method.

In the present study, a fuzzy control for feedrate scheduling based on curvature and curvature variation is proposed. The contributions are (1) using fuzzy control to effectively schedule a reasonable feedrate and (2) developing an average filter to reduce jerks to avoid excessive impact on the machine. The remainder of this paper is organized as follows. Section 2 describes materials and methods which includes fuzzy control for feedrate scheduling. Section 3 presents the experimental results. Finally, Section 4 presents the conclusions of this study, and future research directions are recommended.

\section{Materials and methods}

In this study, cutting experiments are performed with three shapes: $\infty$-shaped, trident-shaped, and butterfly-shaped curves. Firstly, the machining shapes are 
disassembled into discrete coordinate points and converted into processing programs, next, the machining programs extract features from the curvature and curvature variation. After obtaining the required characteristic values, input those values into the fuzzy controller for feedrate scheduling to obtain the federate. Subsequently, an average filter is used to adjust the final feedrate and input the final feedrate in the machining program for actual cutting. Finally, the cutting workpiece is scanned with an optical three-dimensional scanner and the cutting path error is verified. Fig. 1 shows the experimental procedure of this study.

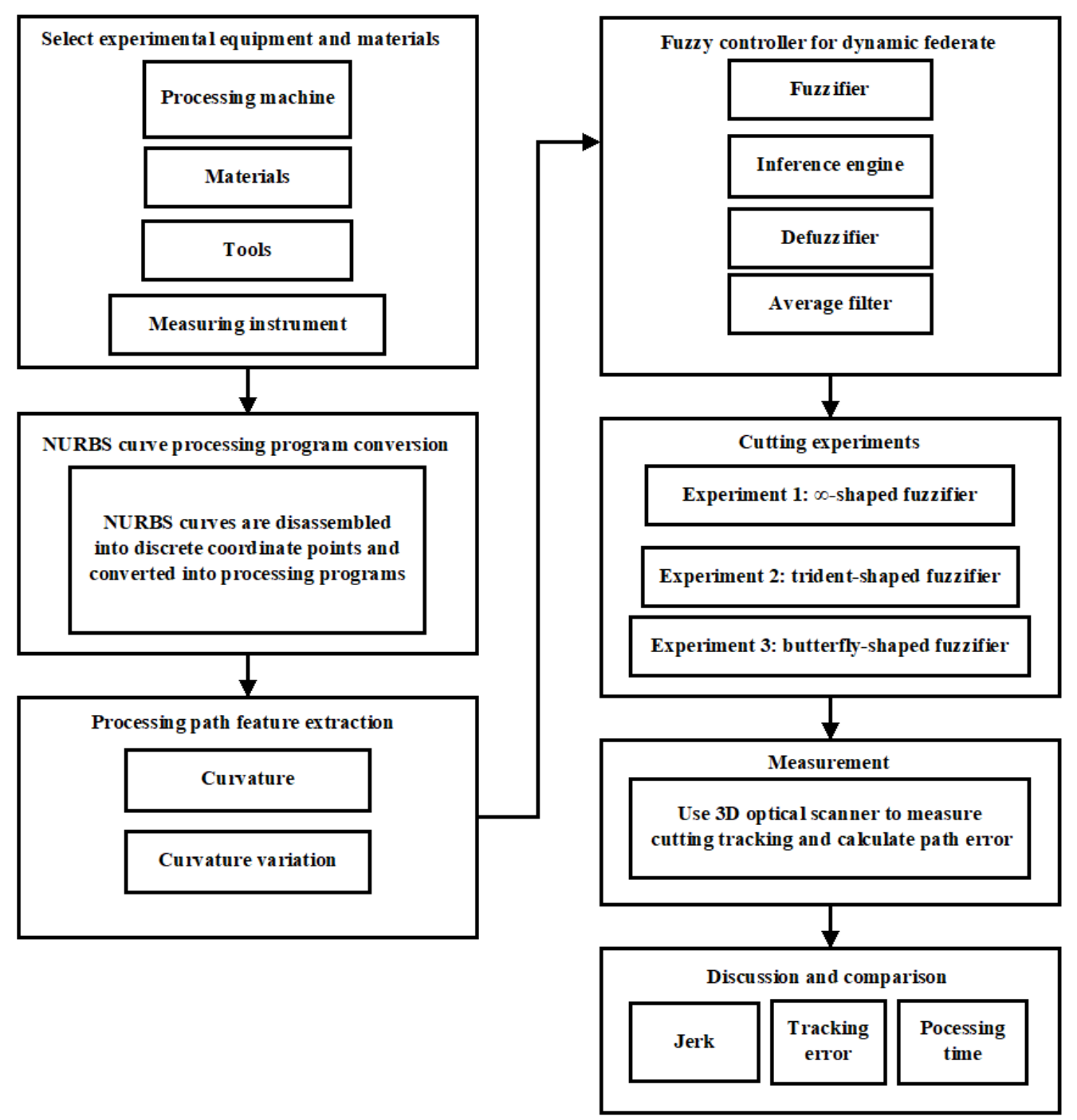

Figure 1. Procedure of fuzzy control for feedrate scheduling

\subsection{Processing machine}

A 5-axis CNC processing machine (VT18, Long Chang Machinery Co., LTD., Taiwan) is used in this study as shown in Fig. 2 and Table 1 lists the parameter settings of the cutting experiments. 


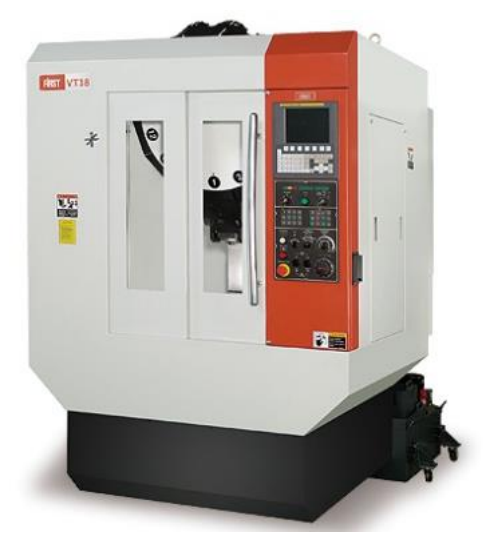

Figure 2. A 5-axis CNC processing machine Table 1. Parameter settings of the cutting experiments

\begin{tabular}{ll}
\hline Conditions & Parameters \\
\hline X-Axis & $450 \mathrm{~mm}$ \\
Y-Axis & $300 \mathrm{~mm}$ \\
Z-Axis & $270 \mathrm{~mm}$ \\
Table size & $500 \mathrm{~mm} \times 350 \mathrm{~mm}$ \\
Max. spindle speed & $10000 \mathrm{rpm}$ \\
Rapid traverse speed & $\mathrm{X} / \mathrm{Y} / \mathrm{Z}: 48 / 4836$ \\
& $\mathrm{M} / \mathrm{min}$ \\
Cutting feedrate & $12 \mathrm{~mm} / \mathrm{min}(" / \mathrm{min})$ \\
Max. table loading & $150 \mathrm{~kg}$ \\
capacity & \\
Controller & FANUC \\
\hline
\end{tabular}

\subsection{Cutting material}

Aluminum alloy 6061 contains magnesium and silicon as the main alloying elements. It has good mechanical properties and welding performance; it is widely used in the manufacture of aircraft structures, boats, and bicycle frames. Moreover, it shows good corrosion resistance; its corrosion resistance is better than that of ordinary carbon steel. Owing to those properties, aluminum alloy 6061 sample with dimensions of 110 $\times 100 \times 25 \mathrm{~mm} 3$ is used as the cutting material in the experiment. However, the melting point of aluminum alloy 6061 is only $\sim 600^{\circ} \mathrm{C}$, generally, solutions as a cutting fluid are sprayed to lower the temperature during processing. Tables 2 and 3 respectively show the mechanical properties and chemical composition of aluminum alloy 6061 .

Table 2. Mechanical properties of 6061 aluminum alloy

\begin{tabular}{ccccc}
\hline $\begin{array}{c}\text { Young's } \\
\text { modulus }\end{array}$ & $\begin{array}{c}\text { Tensile } \\
\text { strength }\end{array}$ & $\begin{array}{c}\text { Elongation at } \\
\text { break }\end{array}$ & $\begin{array}{c}\text { Poisson's } \\
\text { ratio }\end{array}$ & $\begin{array}{c}\text { Brinell } \\
\text { scale }\end{array}$ \\
\hline $68.9 \mathrm{GPa}$ & $\begin{array}{c}124-290 \\
\mathrm{MPa}\end{array}$ & $12-25 \%$ & 0.33 & 30 \\
\hline
\end{tabular}

Table 3. Chemical composition of 6061 aluminum alloy (\%)

\begin{tabular}{ccccc}
\hline $\mathrm{Al}$ & $\mathrm{Mg}$ & $\mathrm{Si}$ & $\mathrm{Fe}$ & $\mathrm{Cu}$ \\
\hline 9598 & 0.81 .2 & 0.40 .8 & 00.7 & 0.150 .4 \\
\hline
\end{tabular}




\subsection{Cutting tool}

A tungsten steel ball knife is used as the cutting tool; it produces a V-shaped groove on the workpiece after cutting. The deepest end point of this groove is the tool tip position used to record the tool movement path. Table 4 lists the specifications of the milling cutter.

Table 4. Specifications of milling cutter

\begin{tabular}{lc}
\hline Specification table & \multicolumn{1}{c}{ Ball-nose } \\
& cutter \\
\hline Overall length (L) & $50 \mathrm{~mm}$ \\
Shank diameter (d) & $1.25 \mathrm{~mm}$ \\
Teeth number (Teeth) & 2 \\
\hline
\end{tabular}

\subsection{Optical three-dimensional (3D) scanner}

The optical 3D scanner (ATOS Core, GOM, Braunschweig, Germany) is used to scan the cutting marks on the workpiece for verifying the performance of the proposed method and its specifications are shown in Table 5.

Table 5. Specifications of optical 3D scanner

\begin{tabular}{lccc}
\hline $\begin{array}{l}\text { Scanning } \\
\text { area }\end{array}$ & $\begin{array}{c}\text { Dot } \\
\text { pitch }\end{array}$ & $\begin{array}{l}\text { Measurement } \\
\text { accuracy }\end{array}$ & Scanning \\
\hline $\begin{array}{l}200^{*} 150 \\
\mathrm{~mm}\end{array}$ & $\begin{array}{c}0.08 \\
\mathrm{~mm}\end{array}$ & $0.001 \mathrm{~mm}$ & $250 \mathrm{~mm}$ \\
\hline
\end{tabular}

\subsection{Non-uniform rational basis spline (NURBS) curve conversion}

NURBS curves were first described by Versprille and were standardized internationally in 1991. According to the Standard for the Exchange of Product Model Data (STEP) promulgated by the International Organization for Standardization (ISO), these curves are the only way to use mathematical expressions as a method to define the geometric shape of a product. NURBS curves have been used often in computeraided design and CAM. A NURBS curve is defined as follows:

$$
C(u)=\frac{\sum_{i=1}^{n} w_{i} N_{i, p}(u) P_{i}}{\sum_{i=1}^{n} w_{i} N_{i, p}(u)}
$$

where $P_{i}$ is the $i^{\text {th }}$ control point, $w_{i}$ is the weight of control point $P_{i}, N_{i, p}(u)$ is the $p$ degree basis spline (B-spline), and $u=\left\{u_{0}, u_{1} \ldots u_{n}\right\}$ are knot vectors, and $N_{i, p}(u)$ can be defined as a recursive function as follows:

$$
\begin{gathered}
N_{i, 0}(u)=\left\{\begin{array}{c}
1, \text { if } u_{i} \leq u \leq u_{i+1} \\
0, \text { otherwise }
\end{array}\right. \\
N_{i, p}(u)=\frac{u-u_{i}}{u_{i+p}-u_{i}} N_{i, p-1}(u)+\frac{u_{i+p+1}-u}{u_{i+p+1}-u_{i+1}} N_{i+1, p-1}(u)
\end{gathered}
$$

To disassemble a NURBS curve into the coordinate feature points required by the machining code, the precision required for the machining segment must first be defined. 
The $u$ lies in the interval [0,1], when 2000 coordinate points are needed to be generated to represent the characteristics of the machining segment, all coordinate points can be obtained by simply inputting the series $u$ with an interval of 0.0005 in the NURBS curve function. Finally, all the coordinate points are written into the numerical control code.

\subsection{Machining path feature extraction}

Studies has shown that the curvature has a great relationship with the machining path error under same feedrate. Therefore, using a lower feedrate in the machining segment with a larger curvature can effectively reduce the machining path error, however, most scholars used the current curvature as the design method for dynamic feed scheduling. With this method it is easy to cause excessive acceleration and deceleration in a machining algorithm with uneven curvature distribution. Thus, this study adds the curvature variation as the second condition to enable the dynamic feed scheduling to perform better acceleration and deceleration.

\subsubsection{Curvature calculation}

The curvature is a variable that describes the degree of curvature of a curve; at least three coordinate points are required to determine its value. Figure 3 shows the curvature with three coordinate points $\left(x_{1}, y_{1}\right),\left(x_{2}, y_{2}\right)$, and $\left(x_{3}, y_{3}\right)$.

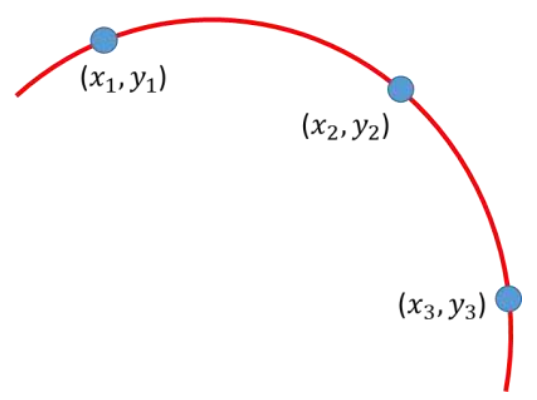

Figure 3. Curvature defined by three coordinate points

Assuming this curve is $s$, its curve equation is given by Eq. (4) with six unknowns $\left(a_{1}, a_{2}, a_{3}, b_{1}, b_{2}, b_{3}\right)$. Eq. (5) can be used to find $t_{a}$ and $t_{b}$ that satisfy Eq. (6).

$$
\begin{gathered}
\left\{\begin{array}{l}
x=a_{1}+a_{2} t+a_{3} t^{2} \\
y=b_{1}+b_{2} t+b_{3} t^{2}
\end{array}\right. \\
t_{a}=\sqrt{\left(x_{2}-x_{1}\right)^{2}+\left(y_{2}-y_{1}\right)^{2}}, t_{b}=\sqrt{\left(x_{3}-x_{2}\right)^{2}+\left(y_{3}-y_{2}\right)^{2}}
\end{gathered}
$$

This gives Eqs. (7)- (8), and an inverse matrix is used to find $\left(a_{1}, a_{2}, a_{3}, b_{1}, b_{2}, b_{3}\right)$. Then, use Eq. (9) to calculate the curvature $\kappa$. 


$$
\begin{gathered}
\left\{\begin{array}{c}
x_{1}=a_{1}-a_{2} t_{a}+a_{3} t_{a}{ }^{2} \\
x_{2}=a_{1} \\
x_{3}=a_{1}+a_{2} t_{b}+a_{3} t_{b}{ }^{2}
\end{array}\right. \\
\left\{\begin{array}{c}
y_{1}=b_{1}-b_{2} t_{a}+b_{3} t_{a}{ }^{2} \\
y_{2}=b_{1} \\
y_{3}=b_{1}+b_{2} t_{b}+b_{3} t_{b}{ }^{2}
\end{array}\right. \\
\kappa=\frac{x^{\prime \prime} y^{\prime}-x^{\prime} y^{\prime \prime}}{\left(\left(x^{\prime}\right)^{2}+\left(y^{\prime}\right)^{2}\right)^{\frac{3}{2}}}=\frac{2\left(a_{3} b_{2}-a_{2} b_{3}\right)}{\left(a_{2}^{2}+b_{2}^{2}\right)^{\frac{3}{2}}}
\end{gathered}
$$

\subsubsection{Curvature variation calculation}

After collecting all curvatures, the curvature variation (Dא) can be calculated using Eq. (10) by sliding the window with a window size (WS) of 30. To enable the fuzzy control for feedrate scheduling to use the maximum curvature in the future as the basis for deceleration, the maximum value is used as the curvature variation. Accordingly, the larger the WS value, the larger is the deceleration zone of the feedrate.

$$
D \kappa_{i}=M A X_{i=n}^{W S}\left(\kappa_{i}\right)
$$

\subsection{Fuzzy controller for dynamic federate scheduling}

The proposed fuzzy control for dynamic feedrate scheduling has two input dimensions: current curvature and amount of curvature variation. After fuzzy inference, the current feedrate can be obtained by defuzzification, and all calculated feedrates are input into the average filter to obtain the machining feedrate. Figure 4 shows the architecture of the fuzzy controller for dynamic feedrate.

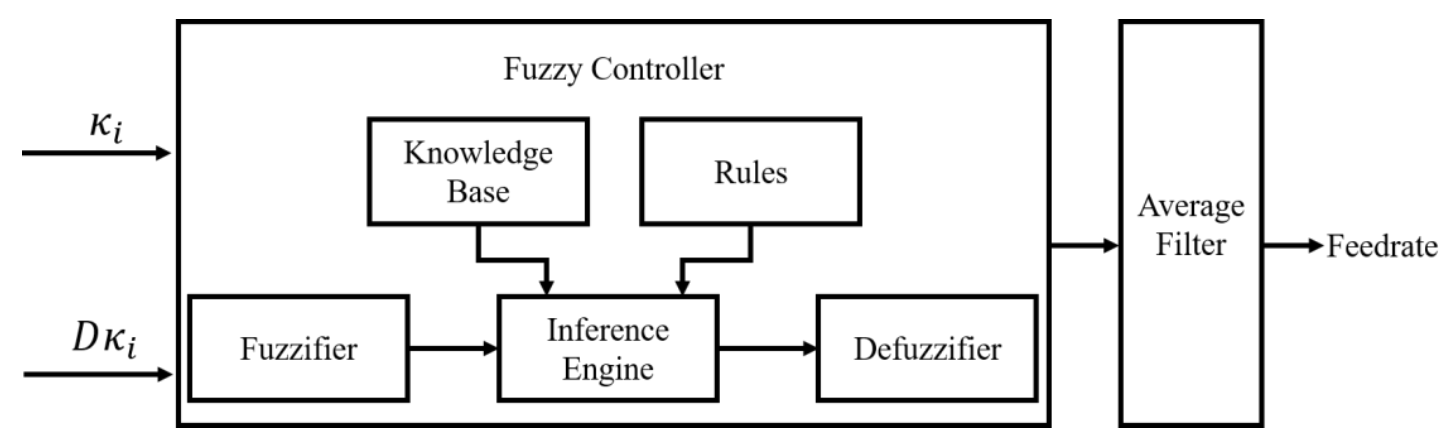

Figure 4. Architecture of fuzzy controller for dynamic federate scheduling

\subsubsection{Fuzzy rules}

\section{A. Fuzzification and membership function}

This study uses a triangular membership function to define the input and output membership functions. The first input is the curvature membership function where $\mathrm{ZO}$ is the minimum curvature, VS is the very small curvature, $\mathrm{S}$ is the small curvature, $\mathrm{M}$ 
is the medium curvature, $\mathrm{B}$ is the large curvature, $\mathrm{VB}$ is the maximum curvature. The other input is curvature variation where $\mathrm{ZO}$ is the very small change, $\mathrm{L}$ is a small change, $\mathrm{M}$ is a medium change, $\mathrm{H}$ is a large change, and $\mathrm{VH}$ is an extremely large change. For the output feedrate membership function, VLF is extremely slow speed, LF is slow speed, MF is medium speed, HF is high speed, VHF is very high speed, VVHF is extremely high speed, and TF is the highest speed. Figure 5 shows the membership functions of the curvature, curvature variation, and feedrate.

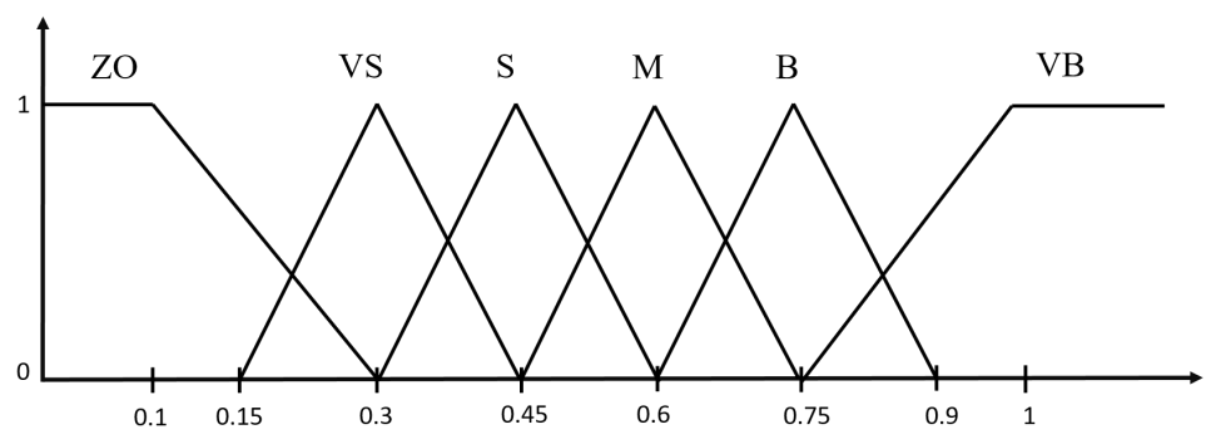

(a) Membership function of curvature $(\kappa|| i)$

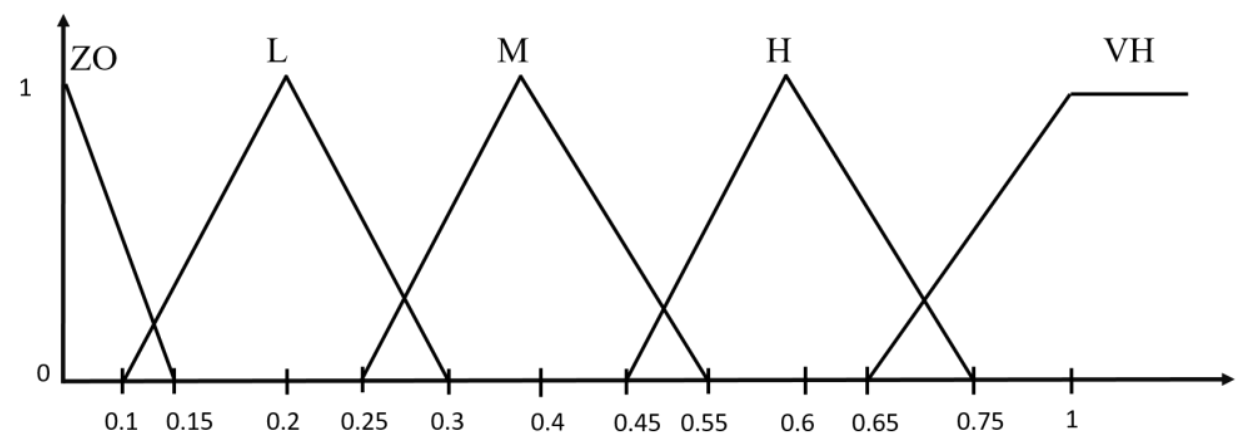

(b) Membership function of curvature variation $(D \kappa|\quad| i)$

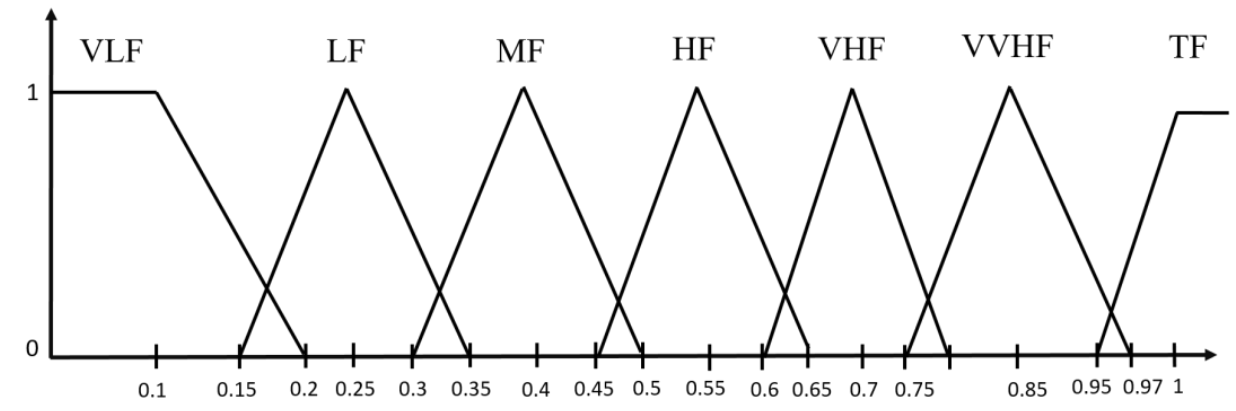

(c) Membership function of feedrate

Figure 5. Membership functions of (a) curvature, (b) curvature variation, and (c) feedrate

When inputting the amount of curvature variation, it is first normalized to the interval $[0,1]$ based on the maximum and minimum values. After many experiments and adjustments, if the curvature variation remains greater than 3 , the curvature variation is 
represented by the maximum value of 3 and is then normalized. The curvature does not need to be normalized and the output is the feedrate percentage. The current feedrate can be obtained by multiplying by the output with the maximum feedrate, and the user is able to adjust the maximum feedrate to meet the machining requirements.

\section{B. Establishment of fuzzy rules}

The two input curvatures $(\kappa|\quad| i)$ and curvature variation $(D \kappa|\quad| i)$ designed in the previous section have six and five membership functions, respectively, and the output feedrate has seven membership functions. The tool needs to decelerate early before entering the high-curvature area; for this purpose, a low feedrate is used in the highcurvature area, and acceleration is started after leaving the high-curvature area, as shown in Figure 6. According to this rule, a total of 30 control rules are designed as shown in Table 6.

$\mathrm{R} 1: \mathrm{IF} \kappa$ is $\mathrm{ZO}$ and $D \kappa$ is ZO THEN Feedrate is TF

R2: IF $\kappa$ is VS and $D \kappa$ is ZO THEN Feedrate is VVHF

$\mathrm{R} 3: \mathrm{IF} \kappa$ is $\mathrm{S}$ and $D \kappa$ is ZO THEN Feedrate is VHF

R4: IF $\kappa$ is $\mathrm{M}$ and $D \kappa$ is ZO THEN Feedrate is HF

R5: IF $\kappa$ is $\mathrm{B}$ and $D \kappa$ is ZO THEN Feedrate is MF

R6: IF $\kappa$ is VB and $D \kappa$ is ZO THEN Feedrate is VLF

R7: IF $\kappa$ is $\mathrm{ZO}$ and $D \kappa$ is L THEN Feedrate is TF

R8: IF $\kappa$ is VS and $D \kappa$ is L THEN Feedrate is VVHF

R9: IF $\kappa$ is $\mathrm{S}$ and $D \kappa$ is L THEN Feedrate is HF

R10: IF $\kappa$ is $\mathrm{M}$ and $D \kappa$ is L THEN Feedrate is HF

R11: IF $\kappa$ is $\mathrm{B}$ and $D \kappa$ is L THEN Feedrate is LF

R12: IF $\kappa$ is VB and $D \kappa$ is L THEN Feedrate is VLF

R13: IF $\kappa$ is $\mathrm{ZO}$ and $D \kappa$ is M THEN Feedrate is VVHF

R14: IF $\kappa$ is VS and $D \kappa$ is M THEN Feedrate is VHF

R15: IF $\kappa$ is $\mathrm{S}$ and $D \kappa$ is M THEN Feedrate is HF

R16: IF $\kappa$ is $\mathrm{M}$ and $D \kappa$ is M THEN Feedrate is MF

R17: IF $\kappa$ is $\mathrm{B}$ and $D \kappa$ is M THEN Feedrate is LF

R18: IF $\kappa$ is VB and $D \kappa$ is M THEN Feedrate is VLF

R19: IF $\kappa$ is ZO and $D \kappa$ is H THEN Feedrate is VVHF

R20: IF $\kappa$ is VS and $D \kappa$ is H THEN Feedrate is VHF

$\mathrm{R} 21$ : IF $\kappa$ is $\mathrm{S}$ and $D \kappa$ is $\mathrm{H}$ THEN Feedrate is HF

$\mathrm{R} 22: \mathrm{IF} \kappa$ is $\mathrm{M}$ and $D \kappa$ is H THEN Feedrate is MF

R23: IF $\kappa$ is B and $D \kappa$ is H THEN Feedrate is VLF

R24: IF $\kappa$ is VB and $D \kappa$ is H THEN Feedrate is VLF

$\mathrm{R} 25$ : IF $\kappa$ is $\mathrm{ZO}$ and $D \kappa$ is VH THEN Feedrate is VVLF 
R26: IF $\kappa$ is VS and $D \kappa$ is VH THEN Feedrate is VVLF

$\mathrm{R} 27$ : IF $\kappa$ is $\mathrm{S}$ and $D \kappa$ is VH THEN Feedrate is MF

$\mathrm{R} 28$ : IF $\kappa$ is $\mathrm{M}$ and $D \kappa$ is VH THEN Feedrate is MF

R29: IF $\kappa$ is B and $D \kappa$ is VH THEN Feedrate is VLF

R30: IF $\kappa$ is VB and $D \kappa$ is VH THEN Feedrate is VLF

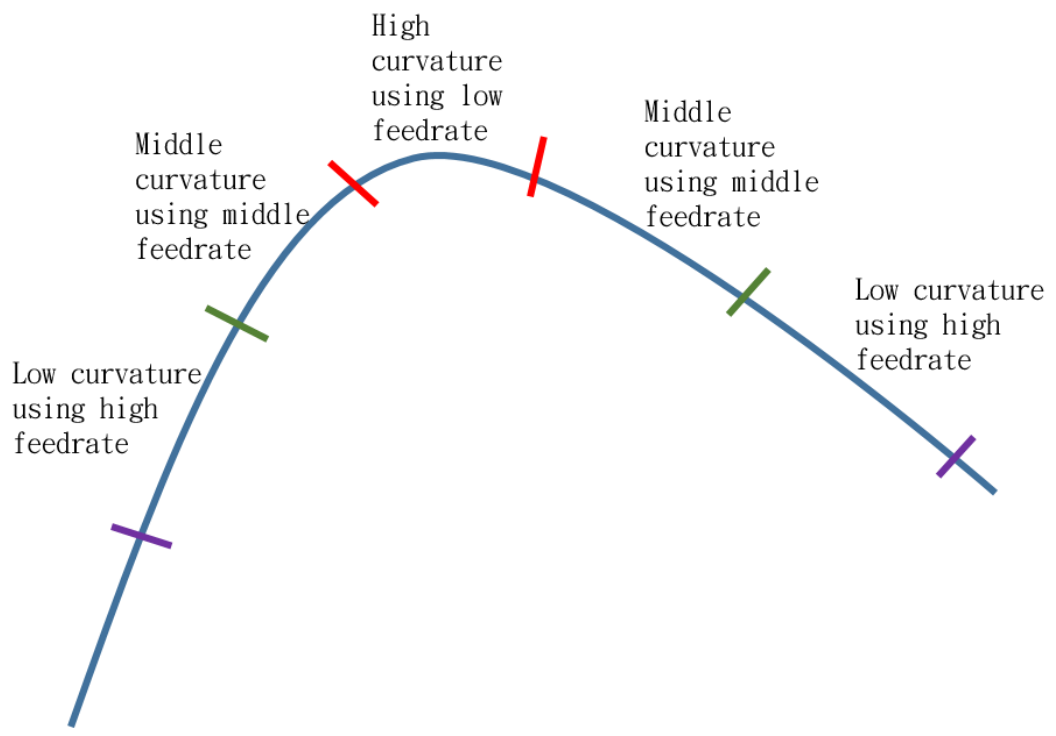

Figure 6. Schematic diagram of machining feedrates

Table 6. Fuzzy control

\begin{tabular}{c|ccccc}
\hline $\begin{array}{c}\text { Curvature } \\
\text { variation } \\
\text { Curvature }\end{array}$ & ZO & L & M & H & VH \\
\hline ZO & TF & TF & VVHF & VVHF & VVLF \\
VS & VVHF & VVHF & VHF & VHF & VVLF \\
S & VHF & HF & HF & HF & MF \\
M & HF & HF & MF & MF & MF \\
B & MF & LF & LF & VLF & VLF \\
VB & VLF & VLF & VLF & VLF & VLF \\
\hline
\end{tabular}

\section{Fuzzy inference and defuzzification}

After designing the input and output membership functions and fuzzy control rules, fuzzy inference and defuzzification are needed to calculate the control variable $F$. In this study, the Mamdani fuzzy model is used for fuzzy inference and the control variable $u_{\text {Feed }}$ derived from the Mamdani fuzzy model is defuzzified to obtain the required precise value. Finally, the center of gravity method is used for defuzzification; the control variable is calculated as follows:

$$
F=\frac{\sum x_{i} \times u_{\text {Feed }}\left(x_{i}\right)}{\sum u_{\text {Feed }}\left(x_{i}\right)}
$$




\subsubsection{Average filter}

According to the output of the fuzzy controller, a preliminary feedrate value can be obtained. For a simple input graph, the curvature rises and falls stably, the feedrate obtained by the controller is considered relatively stable. By contrast, for a complex input graph, the curvature is unstable causing the output feedrate to oscillate up and down. This study introduces an average filter to eliminate unnecessary oscillations in the feedrate curve.

\section{Experimental results}

The $\infty$ shape, trident shape, and butterfly shape graphics [15]-[16], represented as NURBS graphs in Figures 7(a), (b), and (c), respectively, are used in the cutting experiment. Tables 7-9 show the NURBS curve parameters of the $\infty$ shape, trident shape, and butterfly shape, respectively, and the size of those shapes were shrunk to fit into the aluminum workpiece for cutting experiment. The 2000-point coordinates are generated by a resolution of 0.0005 , and the curvature and curvature variation are extracted through the machining path. Figures 8-10 show the curvature and curvature variation of the $\infty$ shape, trident shape, and butterfly shape, respectively.

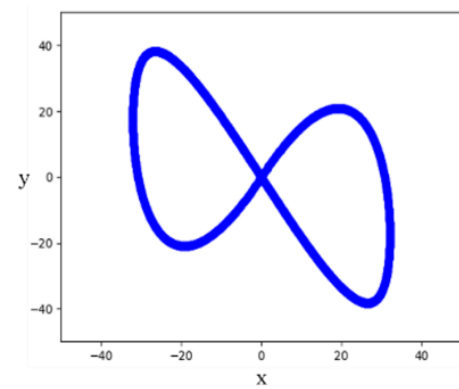

(a)

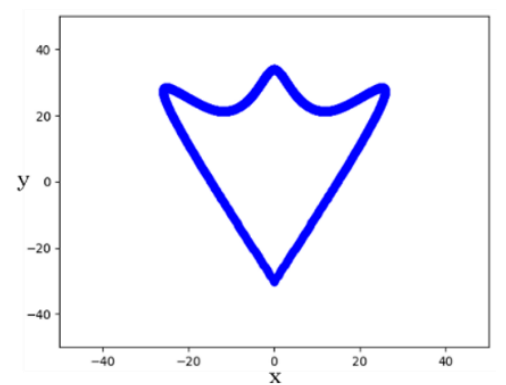

(b)

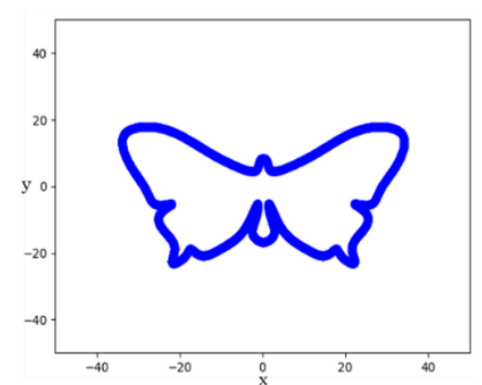

(c)

Figure 7. Experimental cutting graphs: (a) $\infty$ shape, (b) trident shape, and (c) butterfly shape

Table 7. Parameters of $\infty$ shape

\begin{tabular}{lc}
\hline Parameter & Value \\
\hline & {$[0,0,0],[-48,-90,0],[-68,127.5,0]$,} \\
Control point & {$[0,0,0],[68,-127.5,0],[48,90,0],[0$,} \\
& $0,0]$ \\
Knot & $0,0,0,0,0.25,0.5,0.75,1.0,1.0,1.0$, \\
Weight & 1.0 \\
Degree & $0.6,0.6,0.6,0.6,0.6,0.6,0.6$ \\
\hline
\end{tabular}


Table 8. Parameters of trident shape

\begin{tabular}{ll}
\hline Parameter & Value \\
\hline & {$[20,0,0],[40,40,0],[24,16,0],[20$,} \\
Control point & $40,0]$, \\
& {$[16,16,0],[0,40,0],[20,0,0]$} \\
Knot & $0,0,0,0,0.25,0.5,0.75,1,1,1,1$ \\
Weight & $2,2,2,2,2,2,2$ \\
Degree & 3 \\
\hline
\end{tabular}

Table 9. Parameters of butterfly shape

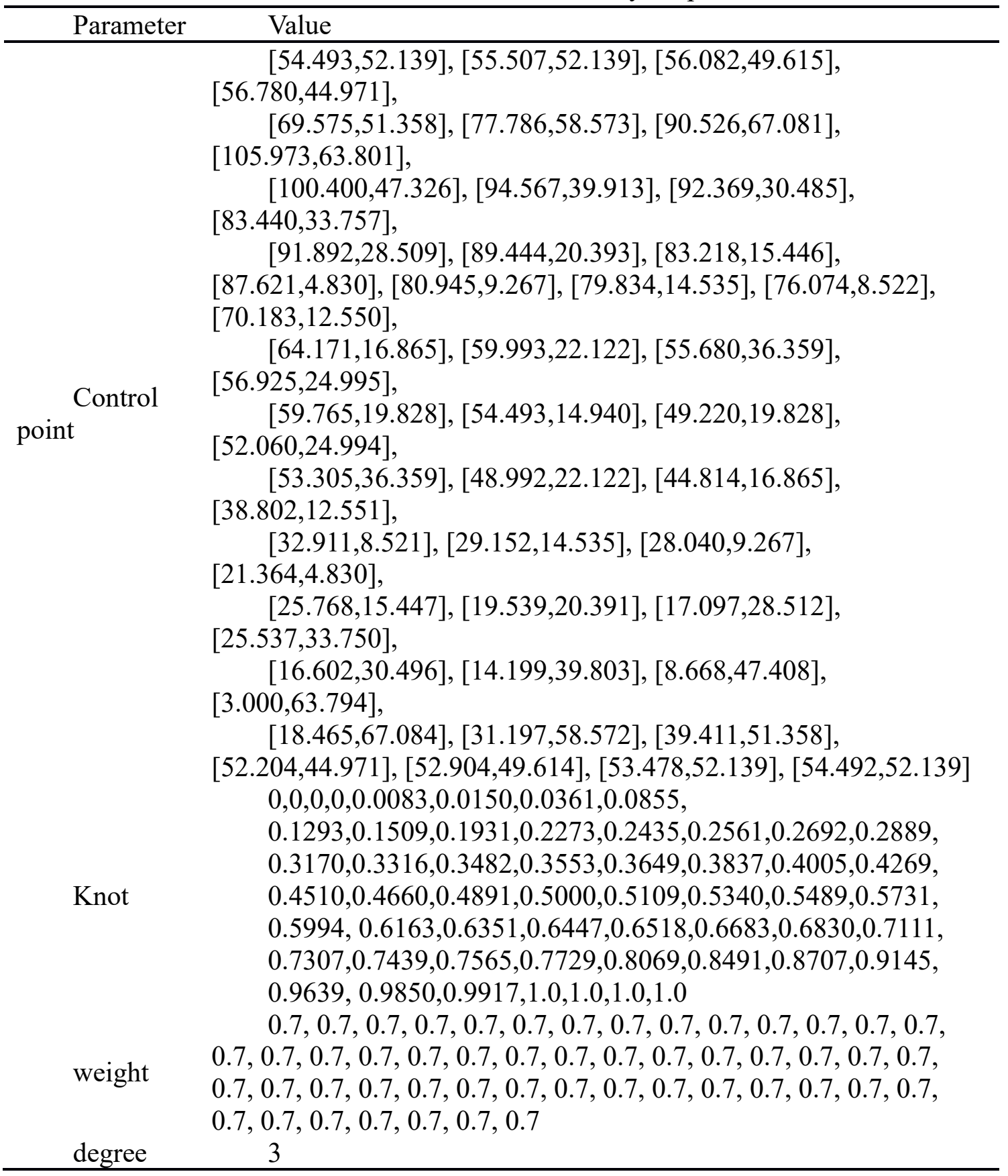




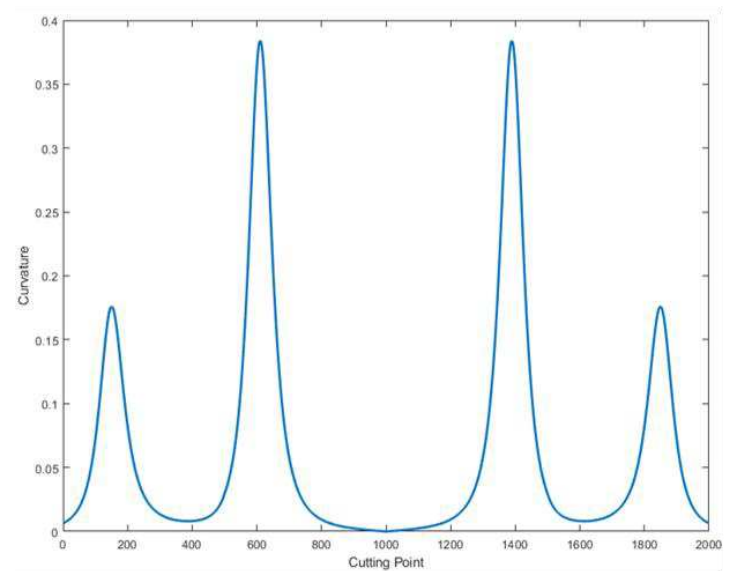

(a)

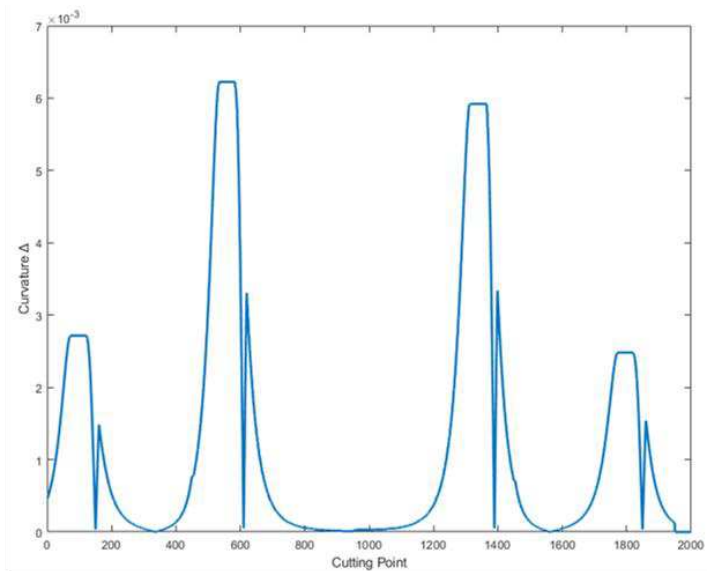

(b)

Figure 8. (a) Curvature and (b) curvature variation of $\infty$ shape

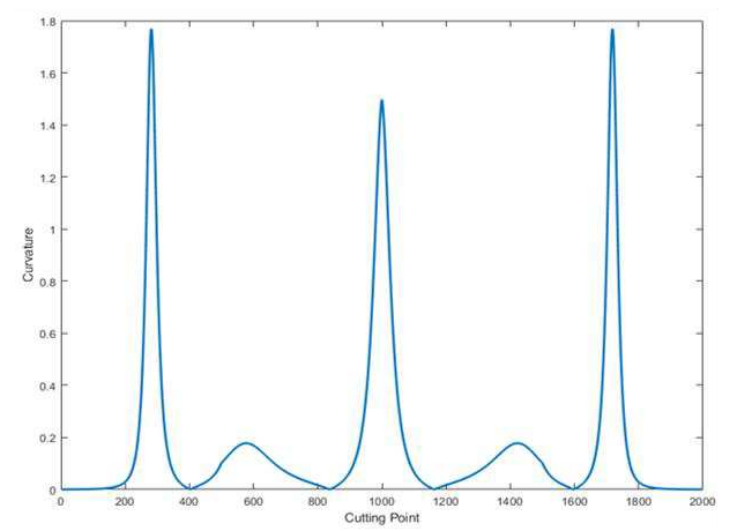

(a)

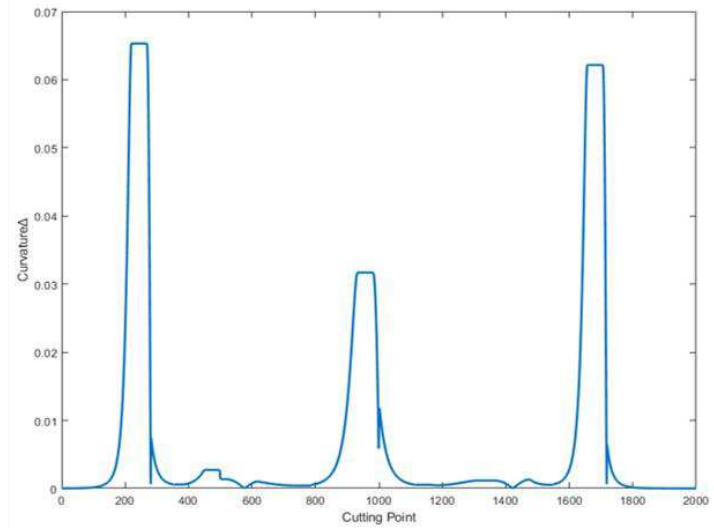

(b)

Figure 9. (a) Curvature and (b) curvature variation of trident shape

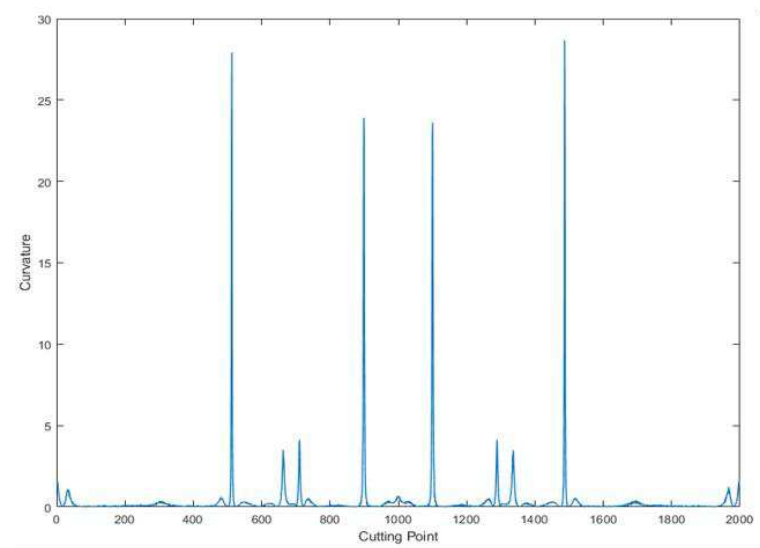

(a)

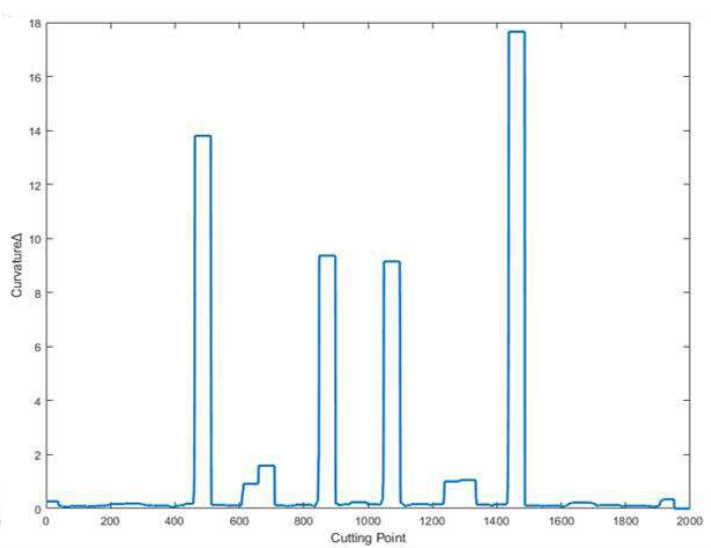

(b)

Figure 10. (a) Curvature and (b) curvature variation of butterfly shape 
To reduce the error caused by tool wear, an aluminum 6061 alloy workpiece with lower hardness is selected for the cutting experiment in the present study. Figure 11(a) shows a photo of the cutting of an aluminum workpiece, and Figure 11(b) shows the aluminum workpiece after cutting.

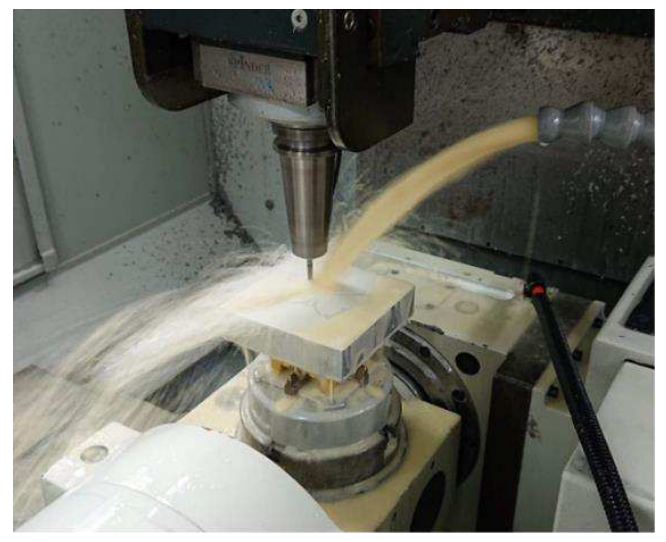

(a)

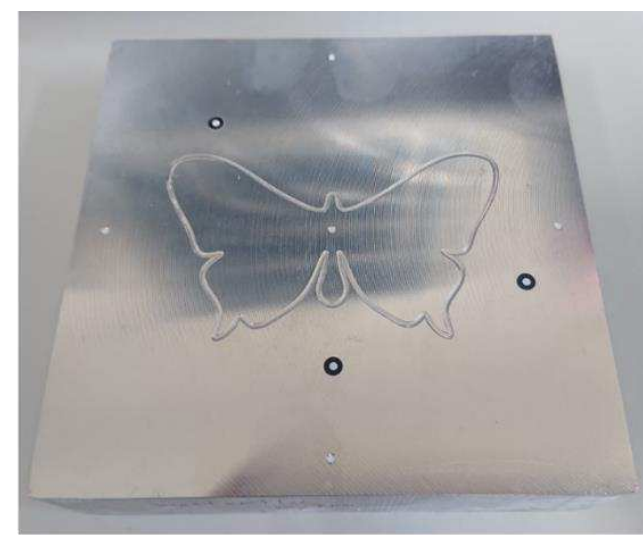

(b)

Figure 11. (a) Cutting of aluminum workpiece and (b) aluminum workpiece after cutting

\subsection{Optical 3D scanner measurement}

Figure 12(a) shows a flowchart of optical three-dimensional measurement. First, the surface of the aluminum workpiece can easily refract light; therefore, a developer for measurement must be sprayed before optical measurement, as shown in Figure 12(b). Figure 12(c) shows the scanning with the optical 3D scanner to obtain the geometric features of the workpiece. Figure 13(d) shows the software output as a binary 3D graphics file. After obtaining the 3D graphics, the deepest coordinate point of the cutting path groove is acquired as the tool tip cutting path. This coordinate is matched to the path of the original machining program, and the shortest distance is calculated as the path error, as shown in Figure 13. 


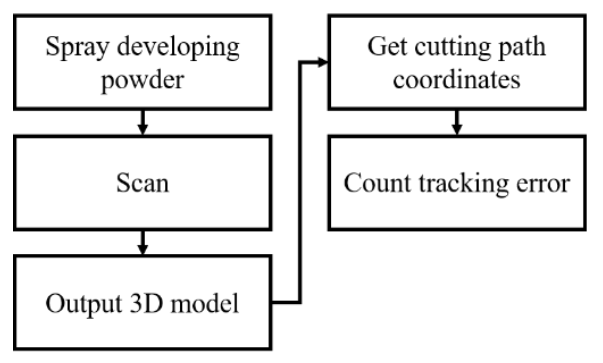

(a)

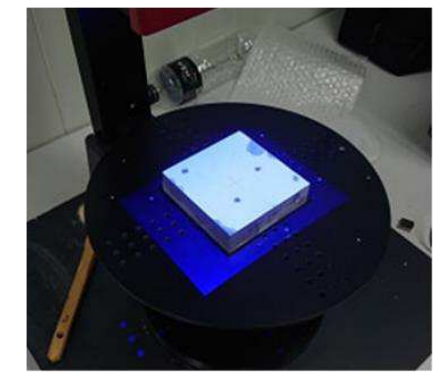

(c)

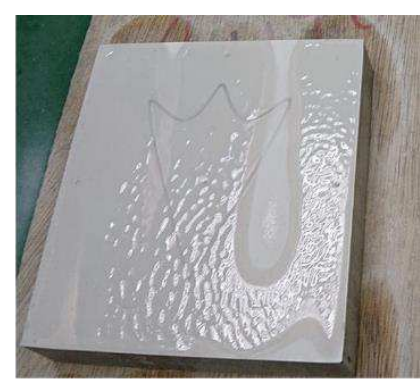

(b)

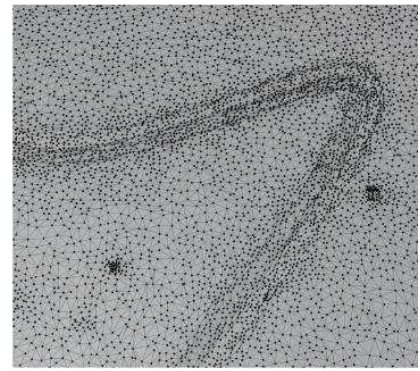

(d)

Figure 12. (a) Flowchart of optical 3D scanner measurement, (b) spraying of developing powder, (c) scanning using optical 3D scanner, and (d) 3D graphics after scanning aluminum workpieces

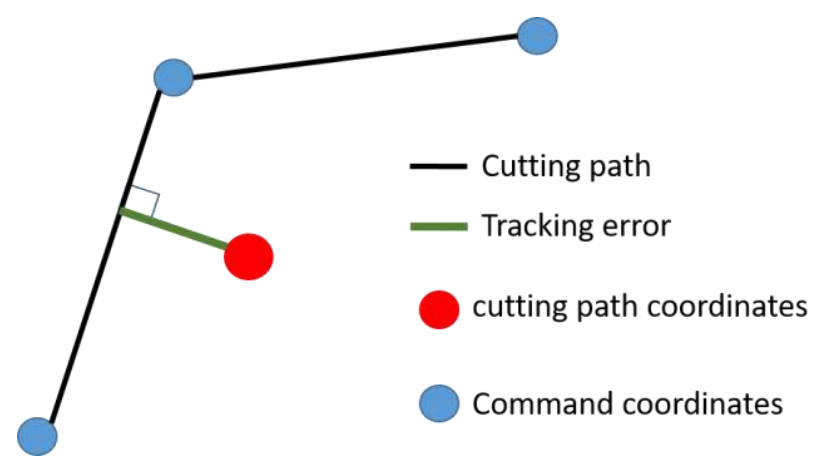

Figure 13. Cutting path error calculation.

This study performs three experiments, and the results were in comparison with the methods proposed by Luan et al. [9], Yeh and Hsu [10], and Giannelli et al. [11]. To performing suitable comparisons, the maximum feedrate in the present study is adjusted to the maximum feedrate proposed by scholars.

\subsection{Experiment 1: Cutting $\infty$ shape}

Figures 14-17 show the feedrate $(\mathrm{m} / \mathrm{min})$, acceleration, and jerk of cutting the $\infty$ shape using the three previous methods and our method, respectively. Table 10 lists the processing time, maximum tracking error, minimum tracking error, and average tracking error. 


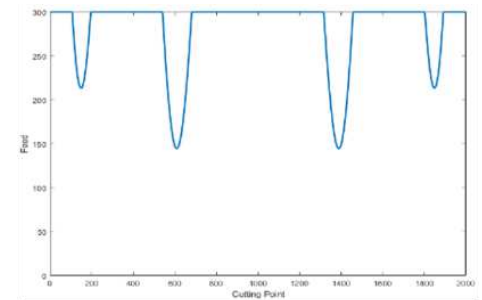

(a)

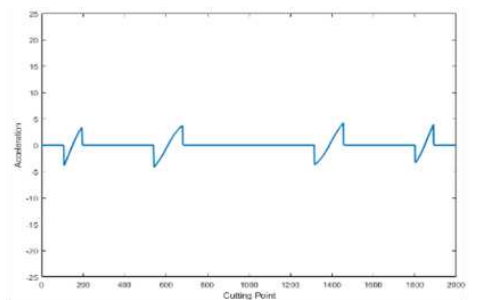

(b)

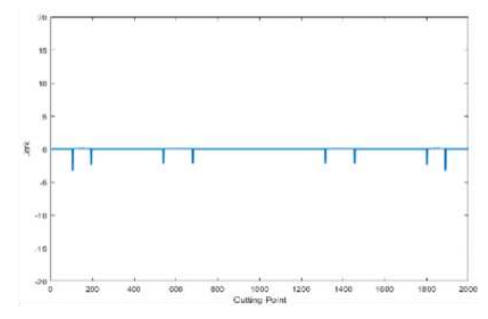

(c)

Figure 14. Cutting $\infty$ shape using method by Luan et al. [9]: (a) feedrate, (b) acceleration, and (c) jerk.

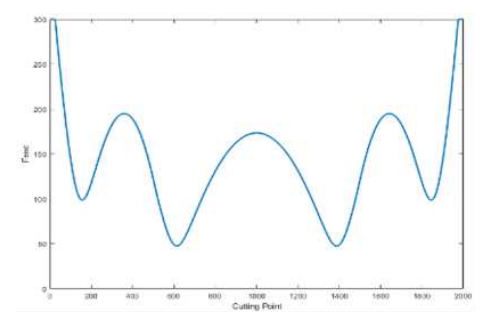

(a)

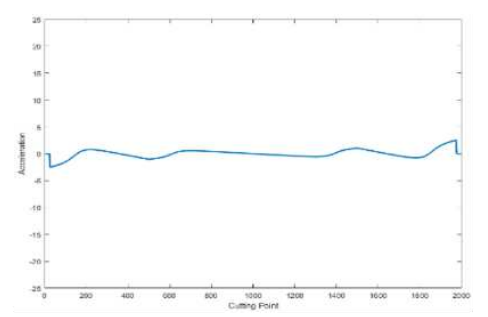

(b)

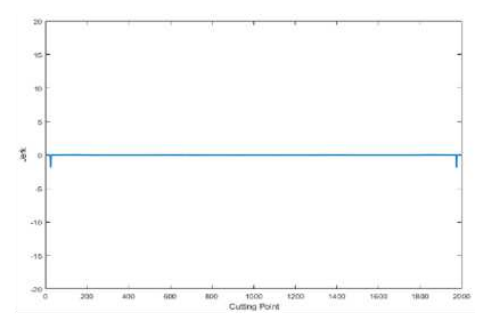

(c)

Figure 15. Cutting $\infty$ shape using method by Yeh and Hsu [10]: (a) feedrate, (b) acceleration, and (c) jerk.

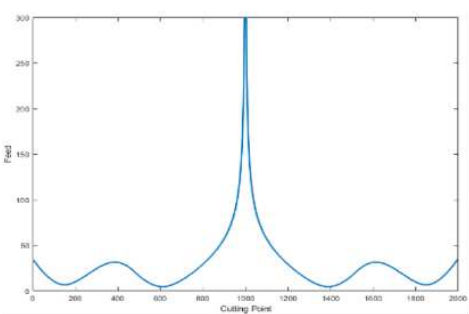

(a)

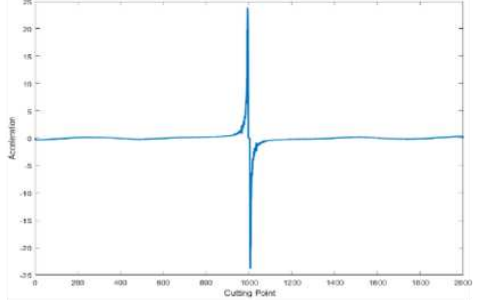

(b)

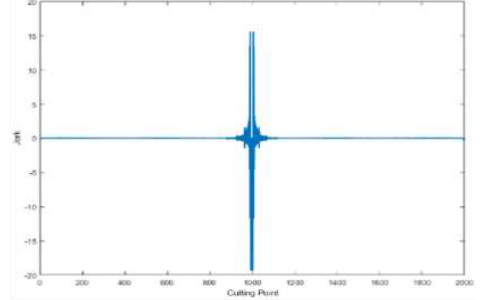

(c)

Figure 16. Cutting $\infty$ shape using method by Giannelli et al. [11]: (a) feedrate, (b) acceleration, and (c) jerk.

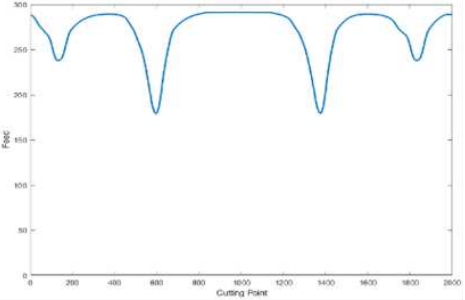

(a)

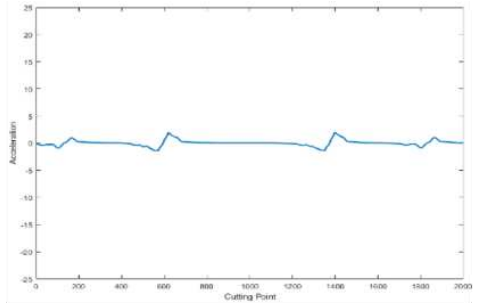

(b)

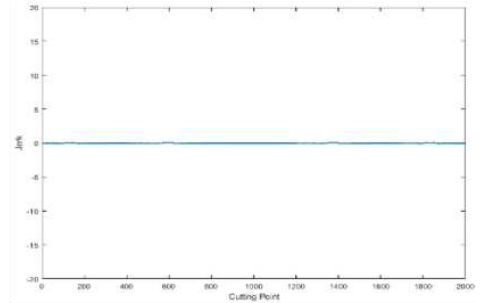

(c)

Figure 17. Cutting $\infty$ shape using our method: (a) feedrate, (b) acceleration, and (c) jerk.

The experimental data indicate that although the method by Giannelli et al. [11] has the largest jerk, the cutting speed is mostly as low as $20 \mathrm{~m} / \mathrm{min}$; therefore, it shows 
the best tracking error while sacrificing the processing time. The proposed method has the same processing time as the method by Luan et al. [9]. The maximum tracking error is better than $0.041 \mathrm{~mm}$, minimum tracking error is better than $0.006 \mathrm{~mm}$, and average tracking error is better than $0.039 \mathrm{~mm}$. Compared with the method by Yeh and Hsu [10], the maximum tracking error is less than $0.004 \mathrm{~mm}$, minimum tracking error is better than $0.001 \mathrm{~mm}$, and average tracking error is less than $0.005 \mathrm{~mm}$; however, our method requires only half the processing time.

Table 10. Tracking error and processing time of $\infty$ shape

\begin{tabular}{llllll}
\hline & $\begin{array}{l}\text { Max speed } \\
(\mathrm{m} / \mathrm{min})\end{array}$ & \multicolumn{2}{l}{ Tracking Error $(\mathrm{mm})$} & \multirow{2}{*}{ Time (s) } \\
\cline { 3 - 5 } & MAX & MIN & Average & \\
\hline Luan et al. [9] & 300 & 0.097 & 0.012 & 0.067 & 62 \\
\hline Yeh and Hsu [10] & 300 & 0.052 & 0.007 & 0.023 & 122 \\
\hline Giannelli et al. [11] & 300 & 0.012 & 0.001 & 0.005 & 907 \\
\hline Our method & 300 & 0.056 & 0.006 & 0.028 & 62 \\
\hline
\end{tabular}

\subsection{Experiment 2: Cutting trident shape}

Figures 18-20 show the feedrate $(\mathrm{m} / \mathrm{min})$, acceleration, and jerk when cutting the trident shape using the three previous methods. Figures 21 and 22 show the feedrate ( $\mathrm{m} / \mathrm{min})$, acceleration, and jerk when cutting the trident shaped using our method at maximum feedrates of 150 and $300 \mathrm{~m} / \mathrm{min}$, respectively. Figure 23 shows a comparison of the jerk using the three previous methods and our method. Table 11 lists the processing time, maximum tracking error, minimum tracking error, and average tracking error.

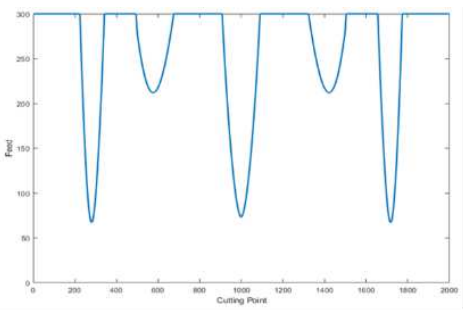

(a)

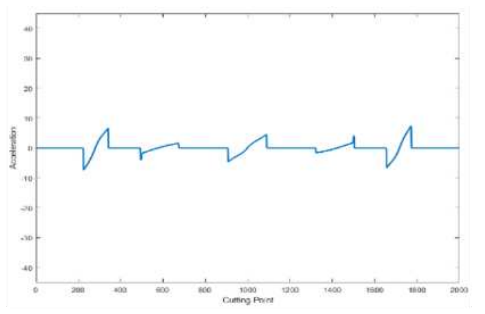

(b)

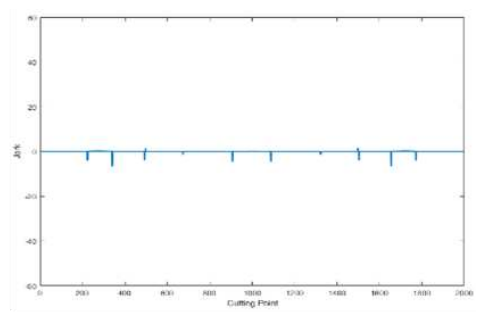

(c)

Figure 18. Cutting trident shape using method by Luan et al. [9]: (a) feedrate, (b) acceleration, and (c) jerk. 


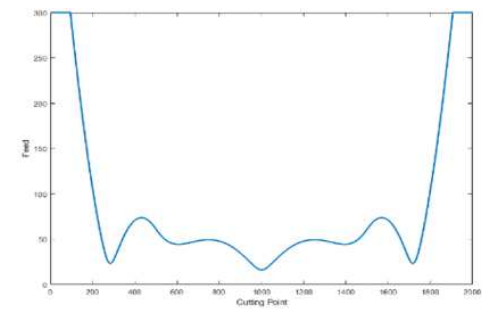

(a)

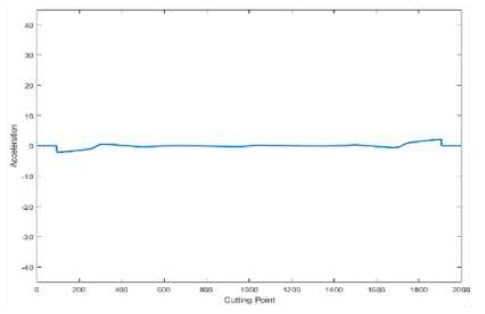

(b)

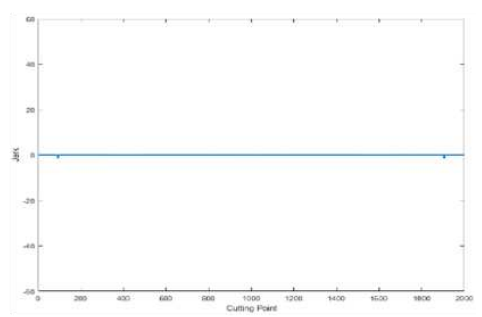

(c)

Figure 19. Cutting trident shape using method by Yeh and Hsu [10]: (a) feedrate, (b) acceleration, and (c) jerk.

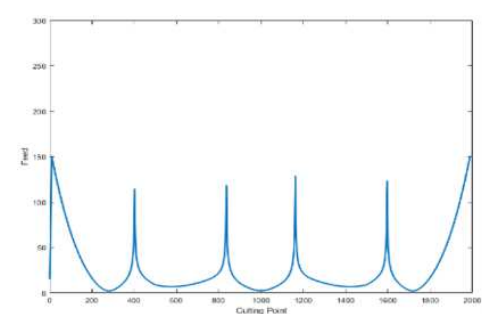

(a)

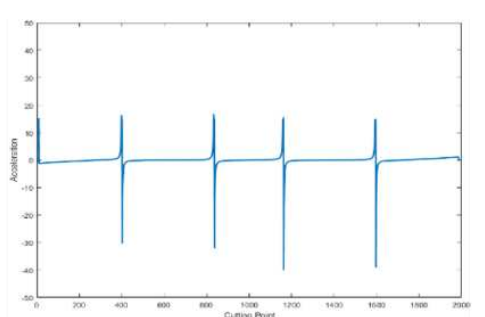

(b)

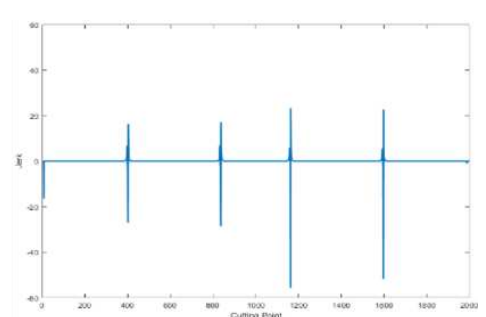

(c)

Figure 20. Cutting trident shape using method by Giannelli et al. [11]: (a) feedrate, (b) acceleration, and (c) jerk.

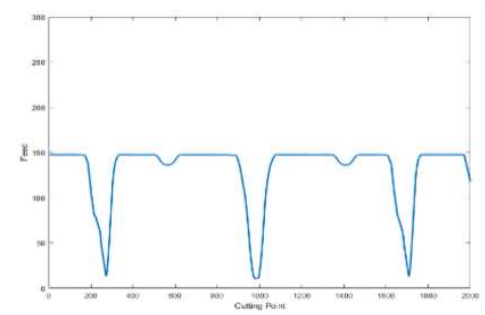

(a)

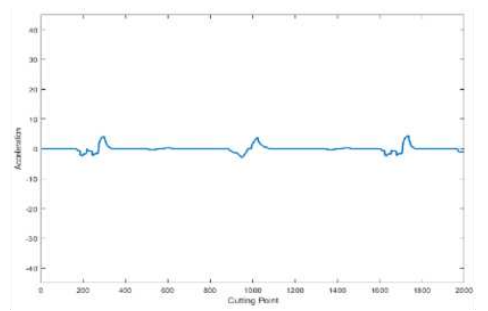

(b)

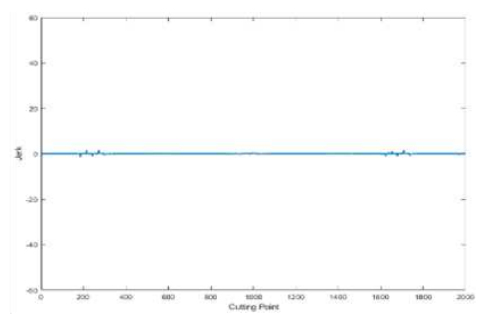

(c)

Figure 21. Cutting trident shape using our method with maximum feedrate of 150 m/min: (a) feedrate, (b) acceleration, and (c) jerk.

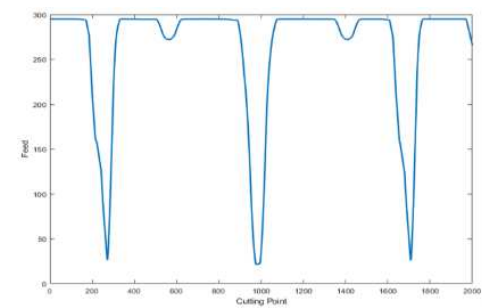

(a)

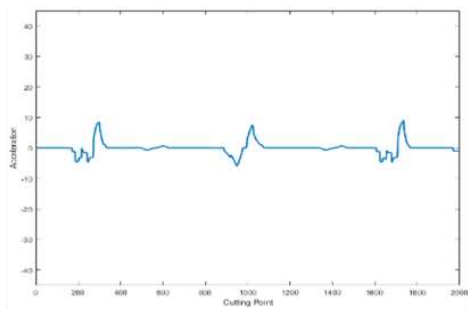

(b)

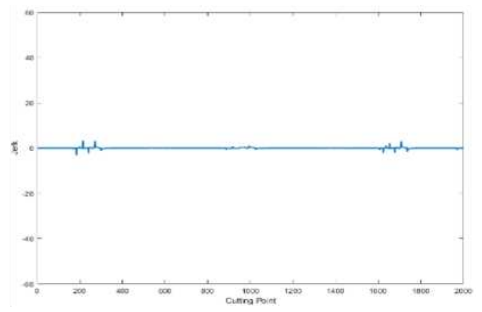

(c)

Figure 22. Cutting trident shape using our method with maximum feedrate of 300 $\mathrm{m} / \mathrm{min}$ : (a) feedrate, (b) acceleration, and (c) jerk. 


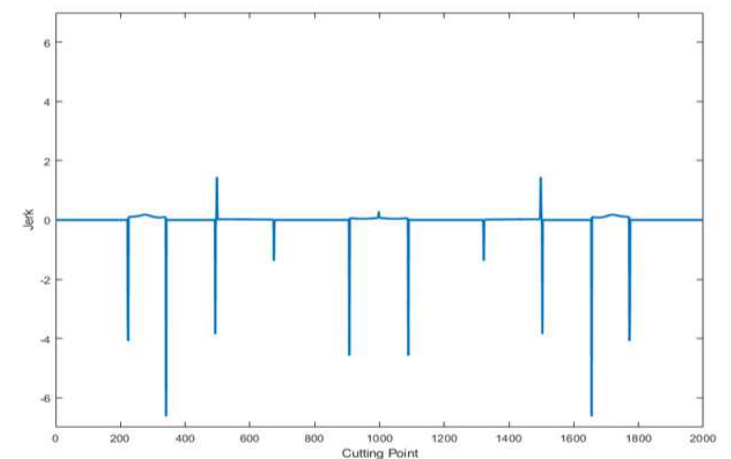

(a)

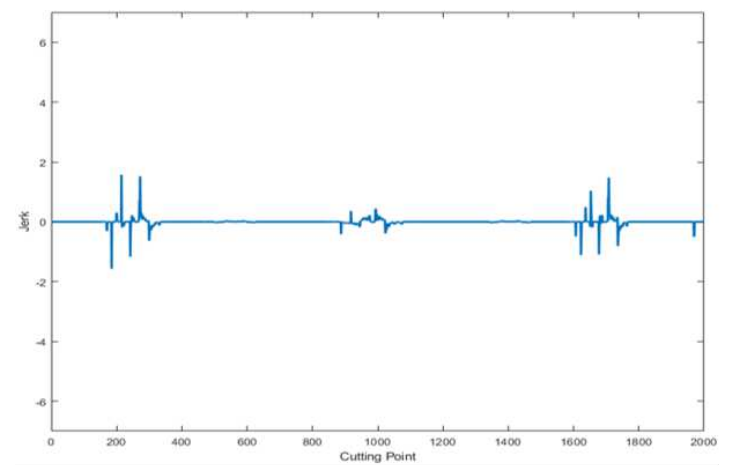

(c)

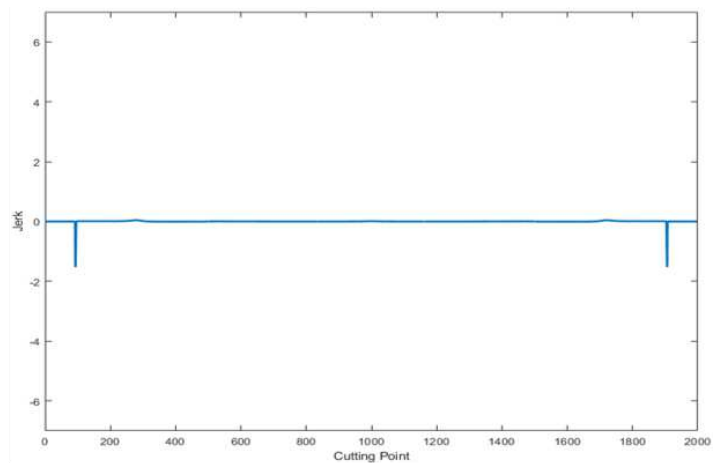

(b)

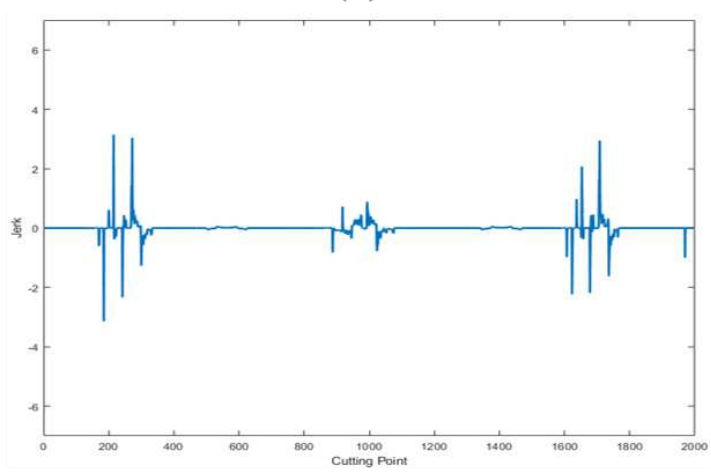

(d)

Figure 23. Jerk when cutting trident shape using (a) method by Luan et al. [9], (b) method by Yeh and Hsu [10], (c) our method with maximum feedrate of $150 \mathrm{~m} / \mathrm{min}$, and (d) our method with maximum feedrate of $300 \mathrm{~m} / \mathrm{min}$.

The experimental data prove that the method by Giannelli et al. [11] has the best path error performance, although it somewhat sacrifices the processing time. The proposed method uses a maximum cutting speed of $300 \mathrm{~m} / \mathrm{min}$, in which case its processing time is less than $1 \mathrm{~min}$ as with the method by Luan et al. [9], and its maximum tracking error is better than $0.029 \mathrm{~mm}$, minimum tracking error is better than $0.001 \mathrm{~mm}$, and average tracking error is better than $0.008 \mathrm{~mm}$. Compared with the method by Yeh and Hsu [10], under the same maximum tracking error and minimum tracking error, the average tracking error is poorer than $0.004 \mathrm{~mm}$ and the processing time is better than $82 \mathrm{~s}$.

Table 11. Tracking error and processing time for trident shape

\begin{tabular}{llllll}
\hline & $\begin{array}{l}\text { Max speed } \\
(\mathrm{m} / \mathrm{min})\end{array}$ & \multicolumn{2}{l}{ Tracking Error $(\mathrm{mm})$} & \multirow{2}{*}{ Time (s) } \\
\cline { 3 - 5 } & 300 & 0.071 & 0.001 & 0.031 & 46 \\
\hline Luan et al. [9] & 300 & MIN & Average & \\
\hline Yeh and Hsu [10] & 300 & 0.022 & $\sim 0$ & 0.008 & 127 \\
\hline Giannelli et al. [11] & 150 & 0.006 & 0.001 & 0.004 & 599 \\
\hline \multirow{2}{*}{ Our method } & 300 & 0.042 & $\sim 0$ & 0.023 & 45 \\
\cline { 2 - 5 } & 150 & 0.022 & 0.001 & 0.012 & 92 \\
\hline
\end{tabular}




\subsection{Experiment 3: Cutting butterfly shape}

Figures 24-26 show the feedrate ( $\mathrm{m} / \mathrm{min})$, acceleration, and jerk when cutting the butterfly shape using the three previous methods. Figures 27-29 show the feedrate $(\mathrm{m} / \mathrm{min})$, acceleration, and jerk when cutting the butterfly shape using our method at maximum feedrates of 58,185 , and $300 \mathrm{~m} / \mathrm{min}$, respectively. Table 12 lists the processing time, maximum tracking error, minimum tracking error, and average tracking error.

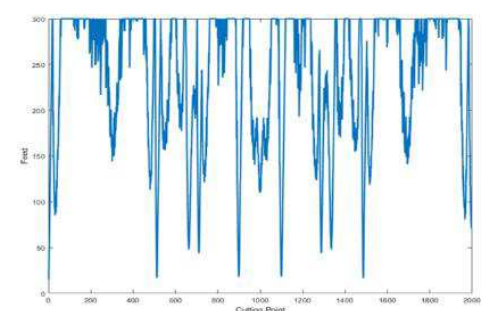

(a)

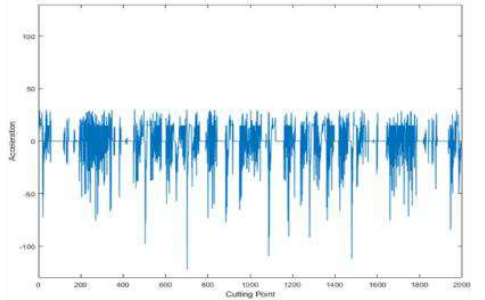

(b)

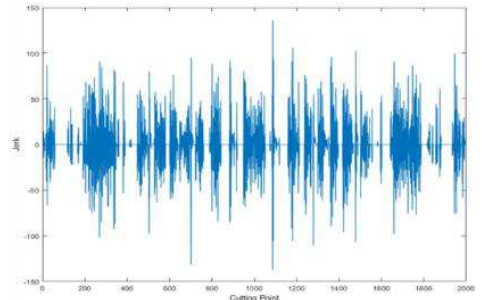

(c)

Figure 24. Cutting butterfly shape using method by Luan et al. [9]: (a) feedrate, (b) acceleration, and (c) jerk.

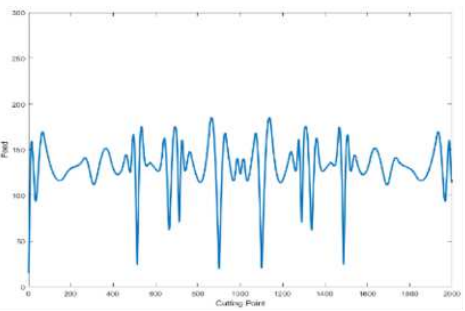

(a)

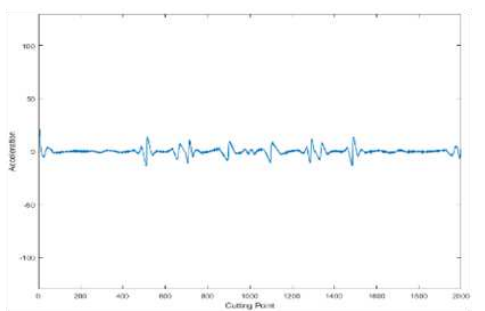

(b)

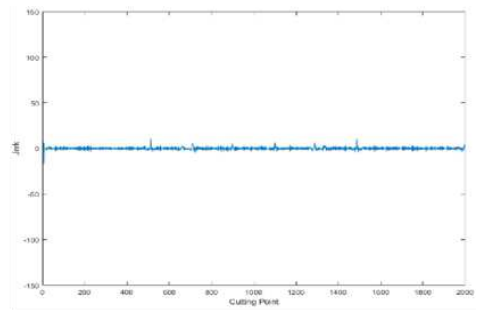

(c)

Figure 25. Cutting butterfly shape using method by Yeh and Hsu [10]: (a) feedrate, (b) acceleration, and (c) jerk.

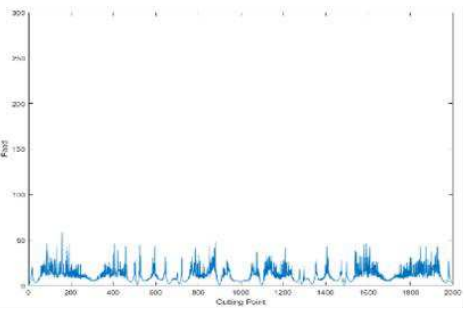

(a)

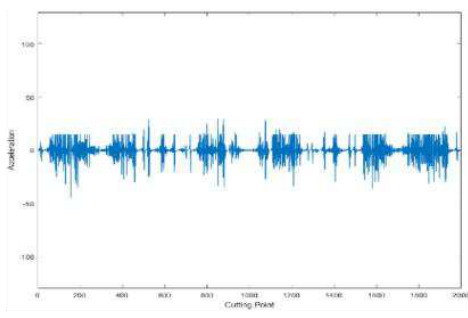

(b)

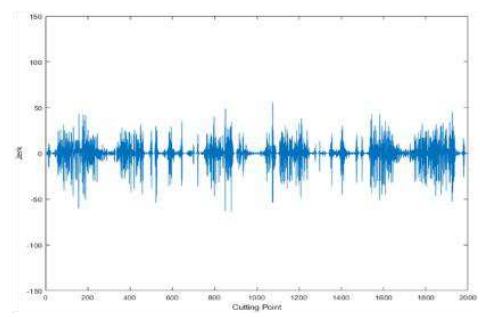

(c)

Figure 26. Cutting butterfly shape using method by Giannelli et al. [11]: (a) feedrate, (b) acceleration, and (c) jerk. 


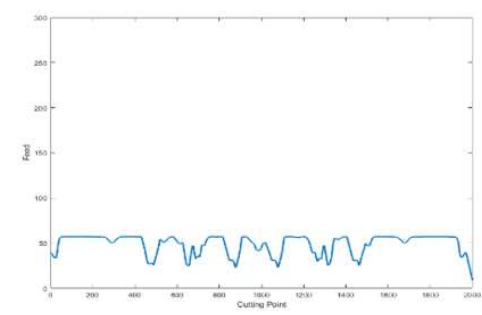

(a)

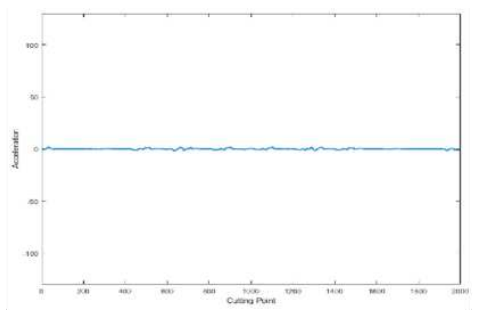

(b)

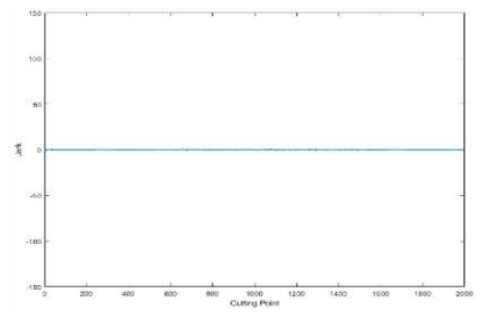

(c)

Figure 27. Cutting butterfly shape using our method with maximum feedrate of 58 $\mathrm{m} / \mathrm{min}$ : (a) feedrate, (b) acceleration, and (c) jerk.

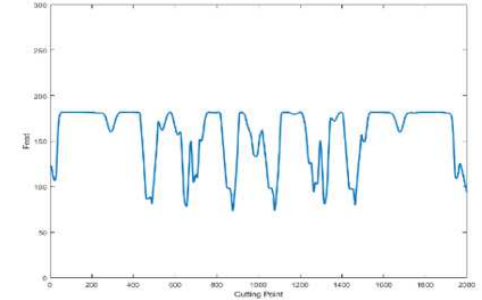

(a)

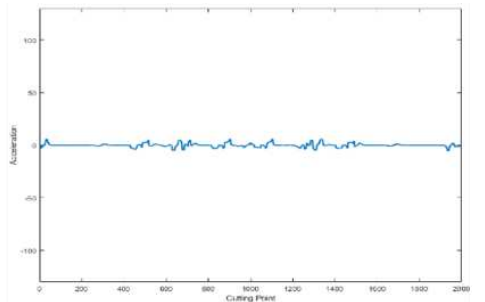

(b)

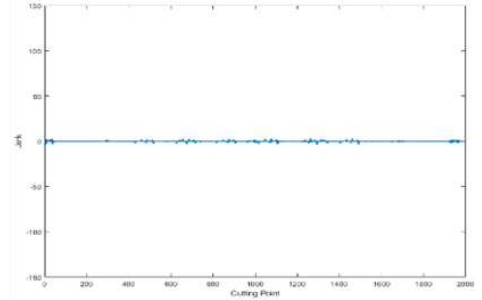

(c)

Figure 28. Cutting butterfly shape using our method with maximum feedrate of 185 m/min: (a) feedrate, (b) acceleration, and (c) jerk.

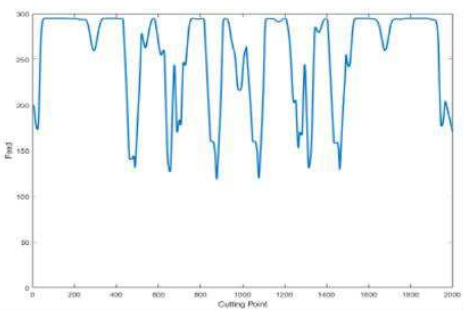

(a)

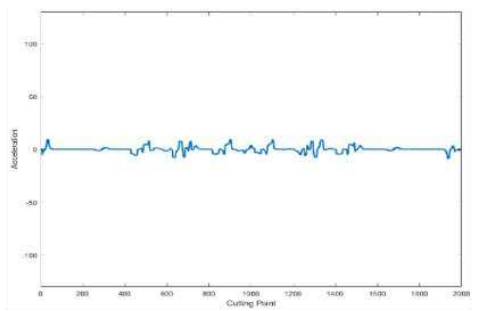

(b)

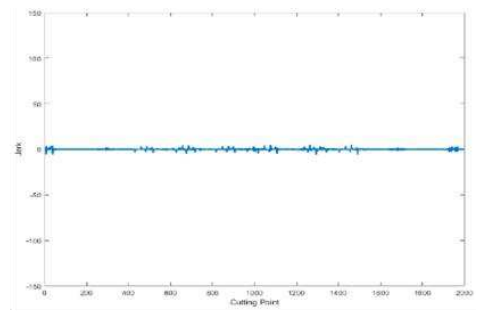

(c)

Figure 29. Cutting butterfly shaped using our method with maximum feedrate of 300 m/min: (a) feedrate, (b) acceleration, and (c) jerk.

The maximum tracking error of $0.004 \mathrm{~mm}$ is better than that of the method by Giannelli et al. [11], average tracking error is better than $0.002 \mathrm{~mm}$, and processing time is half for the same maximum speed. Under the same maximum speed as in the method by Yeh and Hsu [10], the maximum tracking error is better than $0.019 \mathrm{~mm}$, average tracking error is better than $0.003 \mathrm{~mm}$, and processing time is less than $11 \mathrm{~s}$. Our method uses the same maximum speed as the method by Luan et al. [9], and the maximum tracking error is better than $0.029 \mathrm{~mm}$, average tracking error is better than $0.009 \mathrm{~mm}$, and processing time is less than $6 \mathrm{~s}$. 
Table 12. Tracking error and processing time for butterfly shape

\begin{tabular}{llllll}
\hline & $\begin{array}{l}\text { Max speed } \\
(\mathrm{m} / \mathrm{min})\end{array}$ & \multicolumn{2}{l}{ Tracking Error $(\mathrm{mm})$} & \multirow{2}{*}{ Time $(\mathrm{s})$} \\
\cline { 3 - 5 } & 300 & 0.09 & $\sim 0$ & 0.041 & 73 \\
\hline Luan et al. [9] & 185 & 0.061 & $\sim 0$ & 0.029 & 120 \\
\hline Yeh and Hsu [10] & 58 & 0.028 & $\sim 0$ & 0.017 & 729 \\
\hline Giannelli et al. [11] & 58 & 0.061 & $\sim 0$ & 0.032 & 67 \\
\hline \multirow{3}{*}{ Our method } & 300 & 0.042 & $\sim 0$ & 0.026 & 109 \\
\cline { 2 - 5 } & 185 & 0.024 & $\sim 0$ & 0.015 & 360 \\
\cline { 2 - 5 } & 58 & & & & \\
\hline
\end{tabular}

\section{Conclusion}

In the present study, fuzzy control is used to productively schedule a reasonable feedrate, and an average filter is used to effectively reduce jerks to avoid excessive impact on the machine. The experimental results prove that our proposed method can effectively shorten the processing time, improve the cutting precision, and increase the processing speed by up to $50 \%$ while providing better tracking error compared with those of three previously proposed methods.

Dynamic feedrate scheduling is one of the methods that can be used to improve cutting precision and processing time. Previous studies have confirmed that using a smaller feedrate in areas with a larger curvature can effectively increase the cutting precision. In the future, this method could also be applied to noncontact processing such as laser cutting and 3D printing. For fuzzy control, a fuzzy neural network could be implemented to learn the machining parameters of the machine, thereby improving the performance of this method.

\section{Authors' contributions}

Conceptualization, C.-J.L.; methodology, C.-J.L., C.-H. L., and S.-H. Wang; software, C.-J.L. and C.-H. L.; data curation, C.-J.L. and C.-H. L.; writing-original draft preparation, C.-J.L. and C.-H. L.; funding acquisition, C.-J.L. All authors have read and agreed to the published version of the manuscript.

\section{Funding}

This research was funded by the Ministry of Science and Technology of the Republic of China, grant number MOST 109-2218-E-005-002.

\section{Data availability}

The author confirms that the data supporting the findings of this study are available within the paper. 


\section{Compliance with ethical standards}

\section{Conflict of interest}

The authors declare that they have no conflict of interest.

\section{Code availability}

Not applicable

\section{References}

[1] S. KumarSaini, S.-K. Pradhan, "Optimization of multi-objective response during CNC turning using Taguchi-fuzzy application,” Procedia Engineering, vol. 97, pp. 141$149,2014$.

[2] A. Gupta, H. Singh, A. Aggarwal, "Taguchi-fuzzy multi output optimization (MOO) in high speed CNC turning of AISI P-20 tool steel," Expert Systems with Applications, vol. 38, pp. 6822-6828, Jun.2014.

[3] A. Galip Ulsoy, Yehuda Koren, "Control of machining processes," Dynamic Systems Measurement and Control, vol. 115, pp. 301-308, Jun.1993.

[4] L. Wang, X. Yuan, H. Si, F. Duan, "Feedrate scheduling method for constant peak cutting force in five-axis flank milling process," Chinese Journal of Aeronautics, vol. 33, Issue 7, pp. 2055-2069, Oct. 2020.

[5] S.-J. Kim, H.-U. Lee, D.-W. Cho, "Feedrate scheduling for indexable end milling process based on an improved cutting force model," International Journal of Machine Tools and Manufacture, vol. 46, pp. 1589-1597, Oct. 2006.

[6] H.-U. Lee, D.-W. Cho, "Development of a reference cutting force model for rough milling feedrate scheduling using FEM analysis," International Journal of Machine Tools and Manufacture, vol. 47, pp. 158-167, Jan. 2007.

[7] M. Liang, T. Yeap, A. Hermansyah, S. Rahmatia, "Fuzzy control of spindle torque for industrial CNC machining," International Journal of Machine Tools and Manufacture, vol. 43, pp. 1497-1508, Nov. 2003.

[8] S.-C. Kim, S.-C. Chung, "Robust cutting force control using indirect force and disturbance estimators in the end milling process," Proceedings of ASME, vol. 20, pp. 248-251, 1999.

[9] S.-S. Yeh, P.-L. Hsu, "The speed-controlled interpolator for machining parametric curves," Computer-Aided Design., vol. 31, pp. 349-357, Ape.1999.

[10] Z. Luan, G. Jiang, B. Bai, Y. Zhang, X. Mei, “A feedrate pre-schedule NURBS interpolation method for high-speed machining, " 8th IEEE International Conference on Control and Automation, pp. 1672-1677, Jun.2010.

[11] S.-S. Yeh, P.-L. Hsu, “Adaptive-feedrate interpolation for parametric curves with 
a confined chord error," Computer-Aided Design, vol. 34, pp. 229-237, Mar. 2002.

[12] C. Giannelli, D. Mugnaini, A. Sestini, “c^2continuous time-dependent feedrate scheduling with configurable kinematic constraints," Computer-Aided Geometric Design, vol. 63, pp. 78-95, Jul. 2018.

[13] L.- A. Zadeh, "Fuzzy sets," Information and Control, vol. 8, pp. 338-353, Jun.1965.

[14] Z. Miao, W. Li, "A fuzzy system approach of feed rate determination for CNC milling," 2009 4th IEEE Conference on Industrial Electronics and Applications., pp. 1911-1916, 2009.

[15] H. Ni, C. Zhang, S. Ji, T. Hu, Q. Chen, Y. Liu, G. Wang, “A bidirectional adaptive feedrate scheduling method of NURBS interpolation based on S-shaped ACC/DEC algorithm," IEEE Access, vol.6, pp. 63794-63812, Oct. 2018.

[16] M.-T. Lin, M.-S. Tsai, H.-T. Yau, "Development of a dynamics-based NURBS interpolator with real-time look-ahead algorithm," International Journal of Machine Tools and Manufacture., vol.47, pp. 2246-2262, Dec. 2007. 


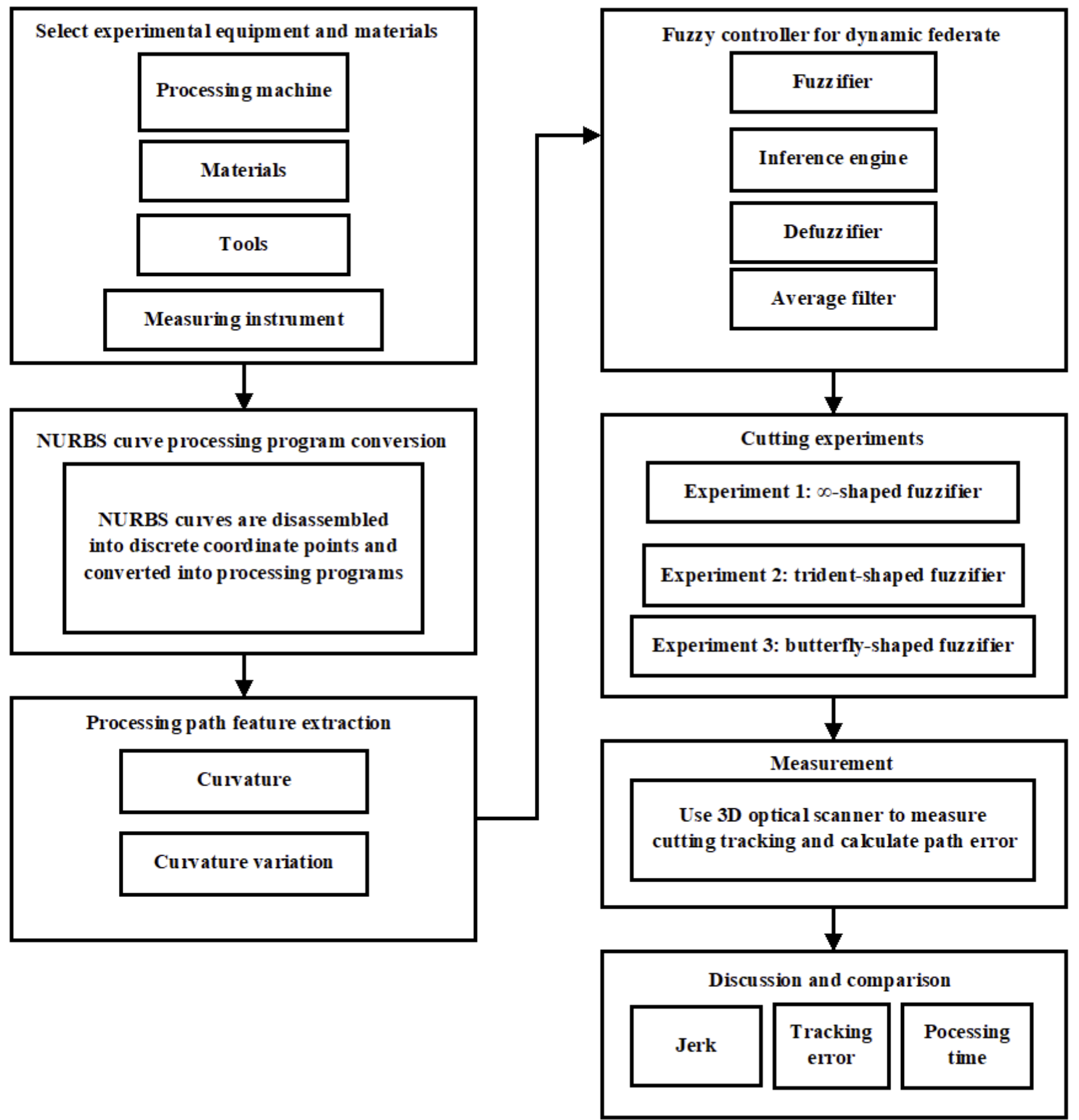

Figure 1 


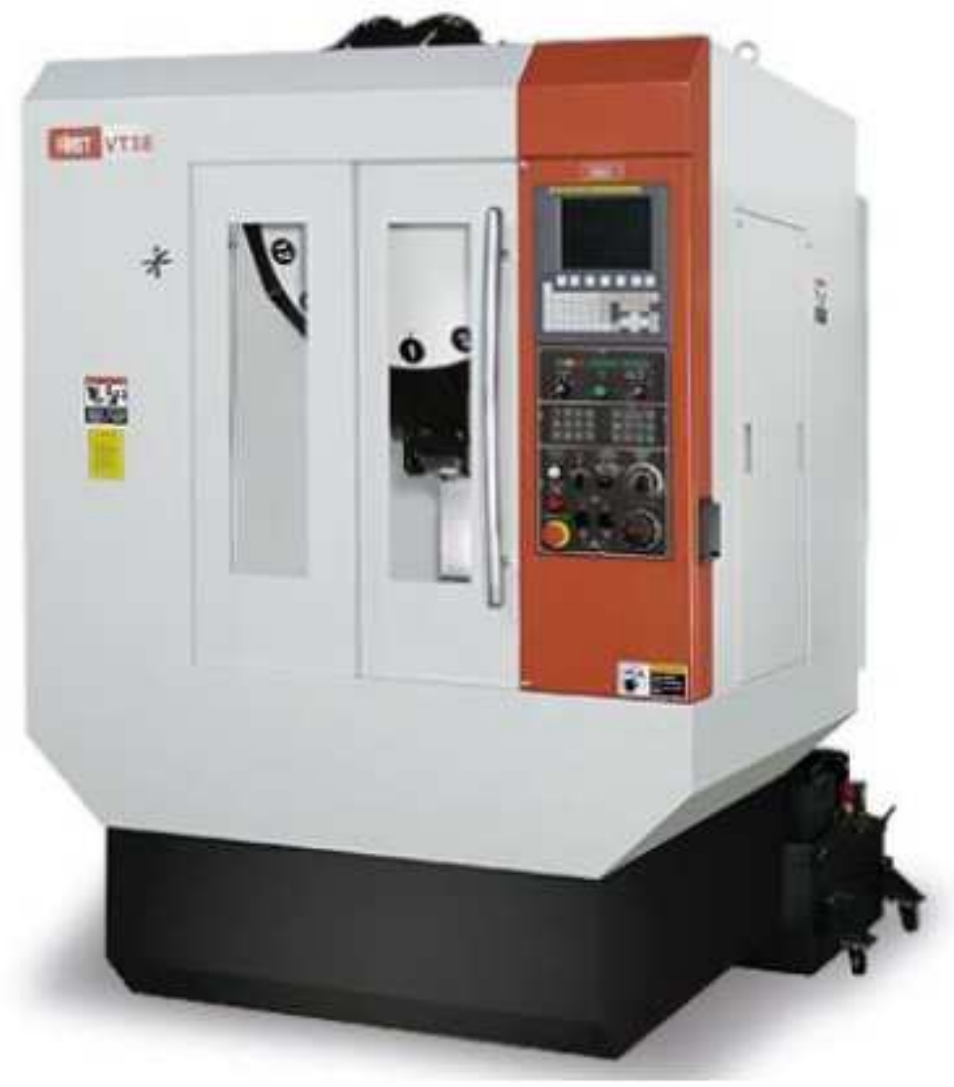

Figure 2

A 5-axis CNC processing machine

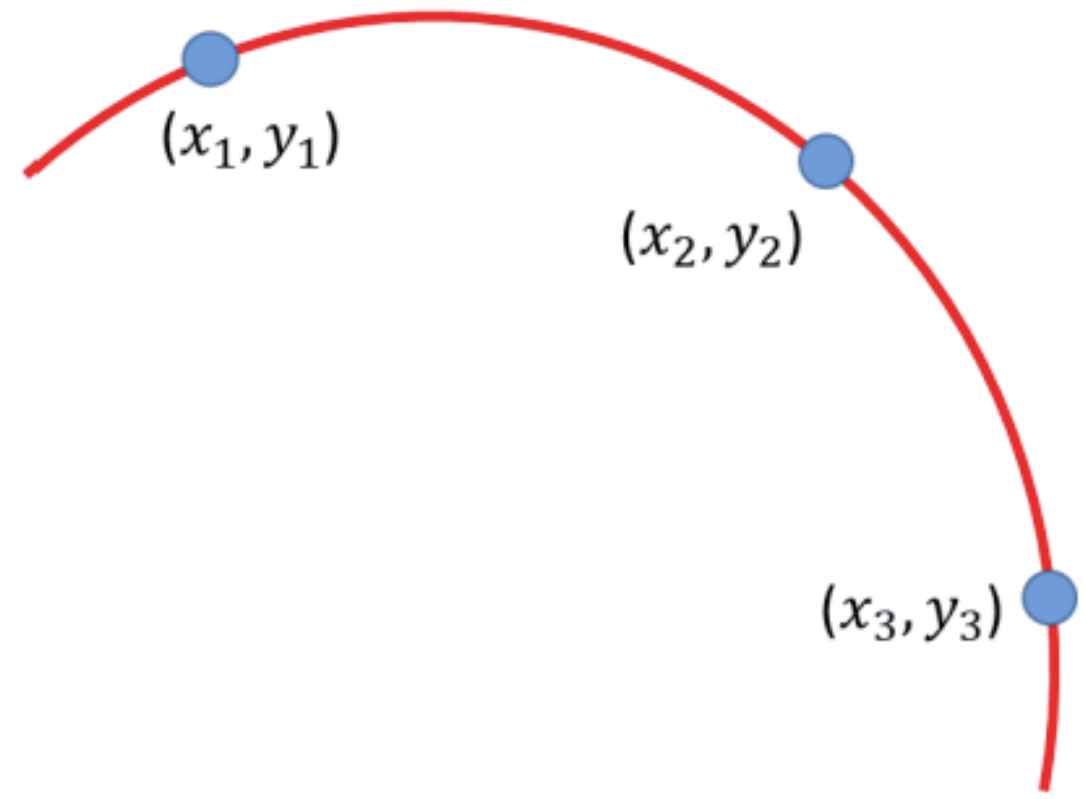

Figure 3 
Curvature defined by three coordinate points

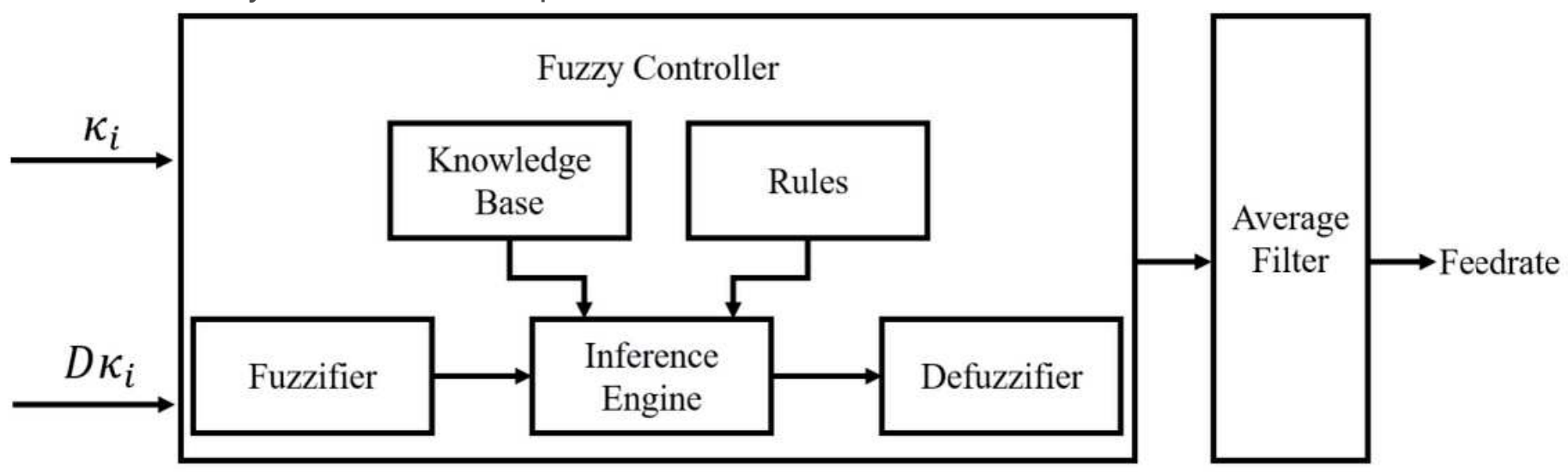

Figure 4

Architecture of fuzzy controller for dynamic federate scheduling 


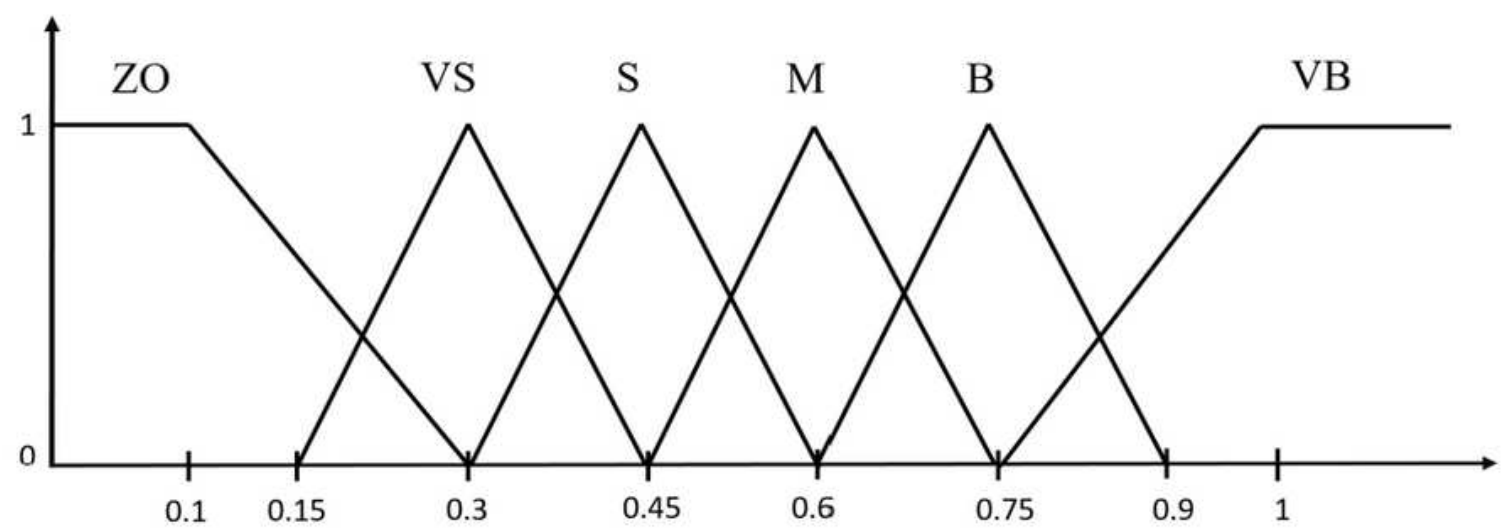

(a) Membership function of curvature $(\kappa|\quad| i)$

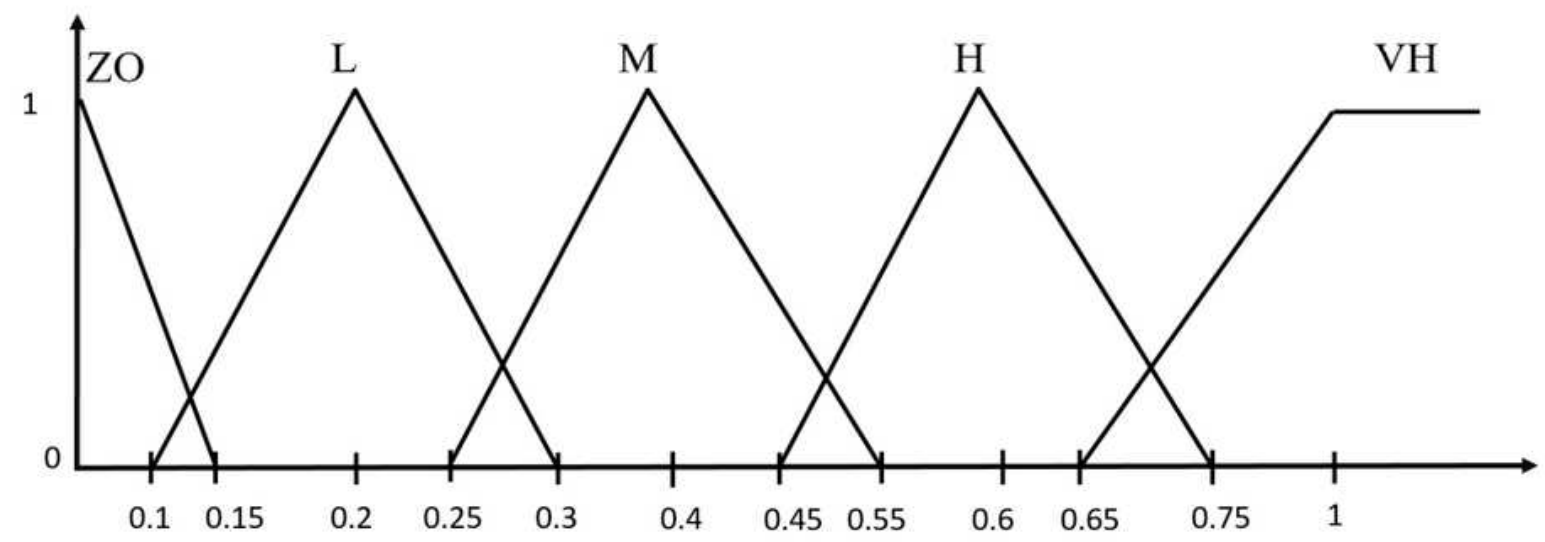

(b) Membership function of curvature variation $(D \kappa|\quad| i)$

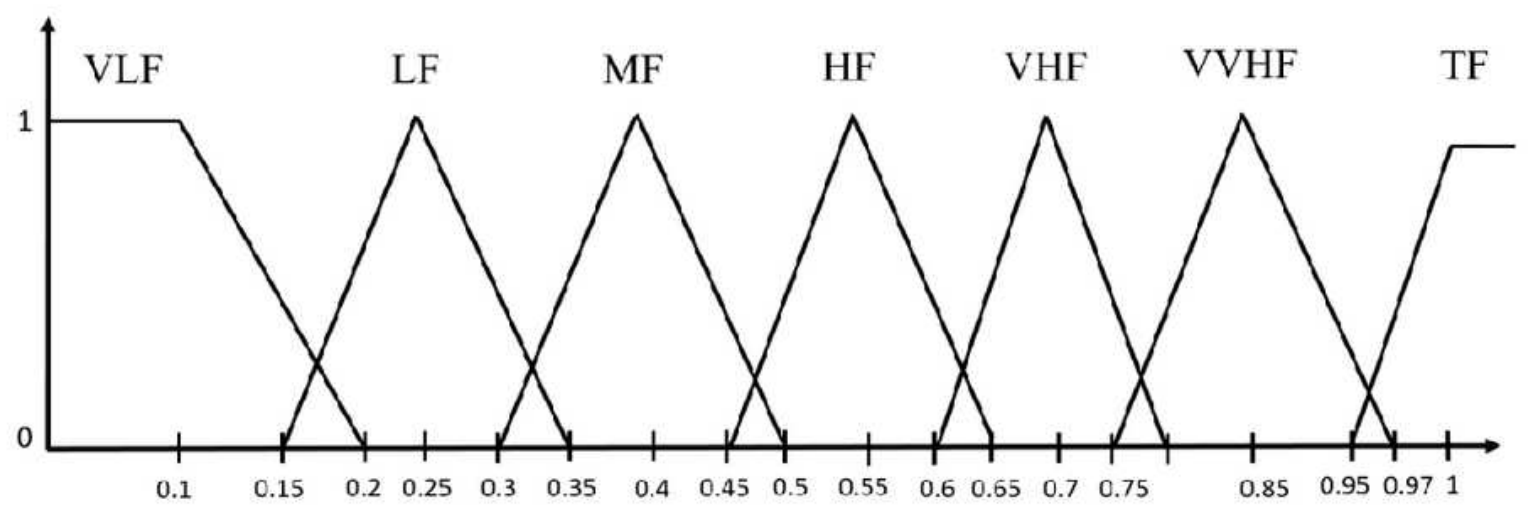

(c) Membership function of feedrate

Figure 5

Membership functions of (a) curvature, (b) curvature variation, and (c) feedrate 


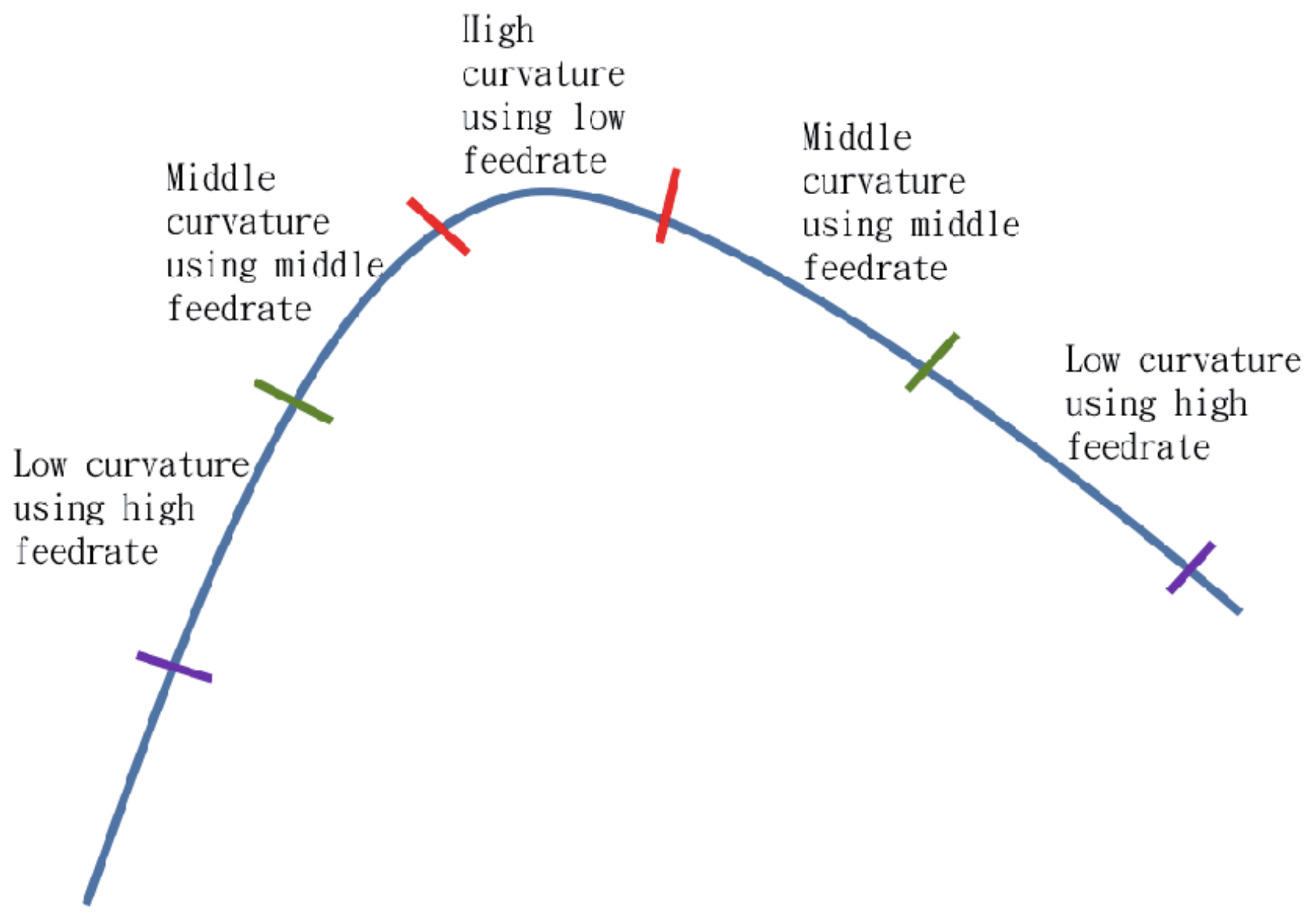

Figure 6

Schematic diagram of machining feedrates

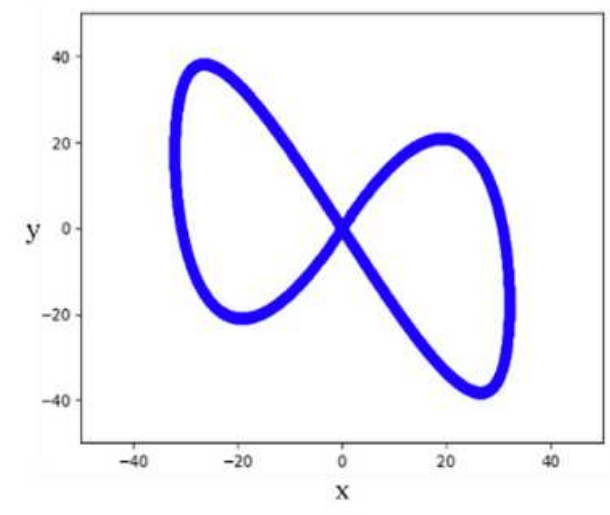

(a)

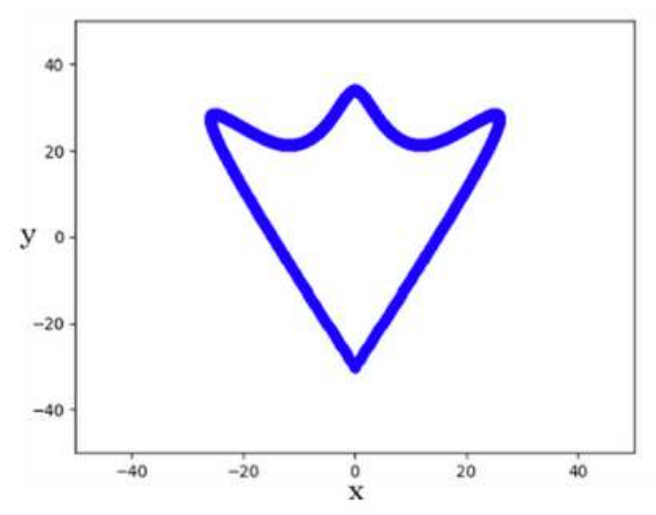

(b)

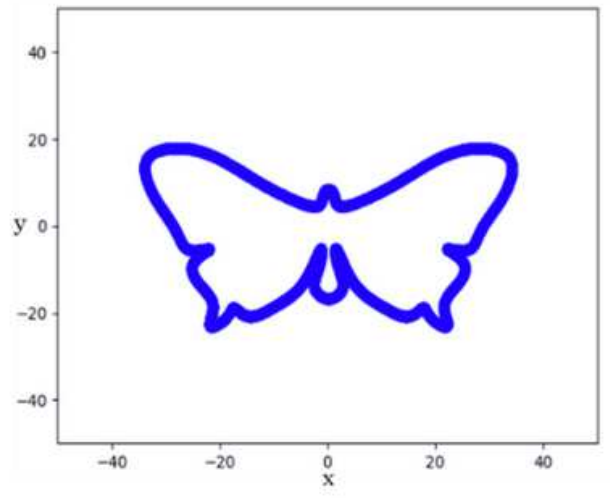

(c)

Figure 7

Experimental cutting graphs: (a) $\infty$ shape, (b) trident shape, and (c) butterfly shape 


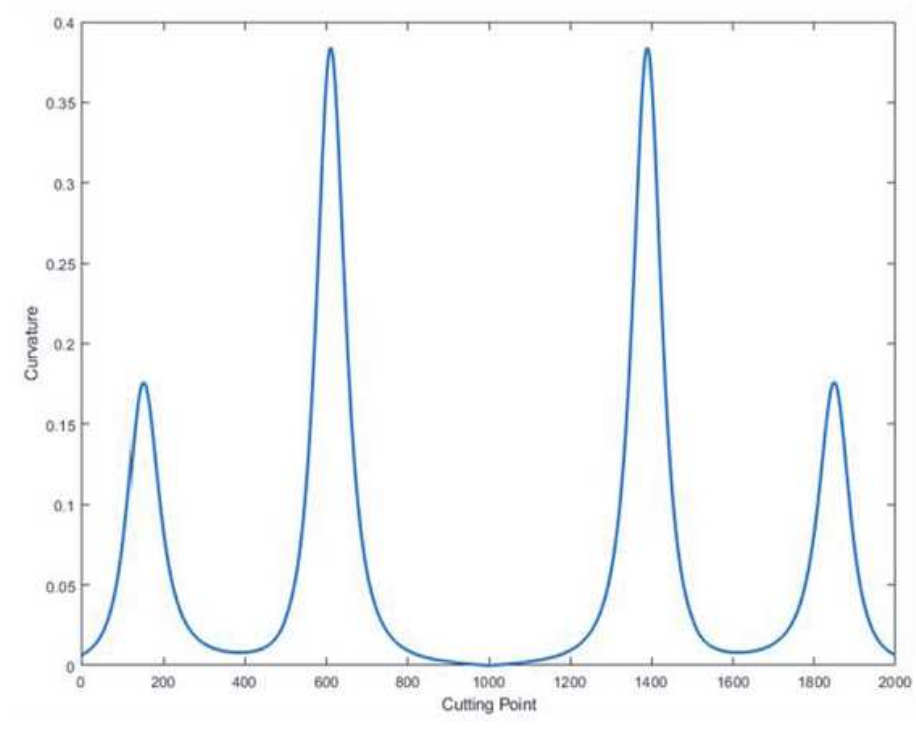

(a)

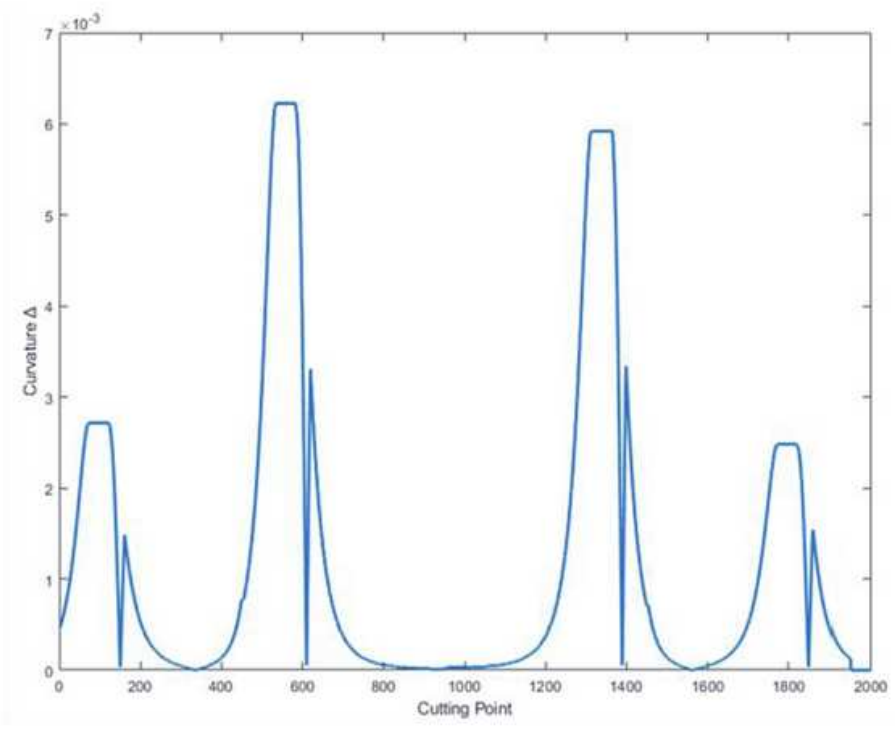

(b)

\section{Figure 8}

(a) Curvature and (b) curvature variation of $\infty$ shape

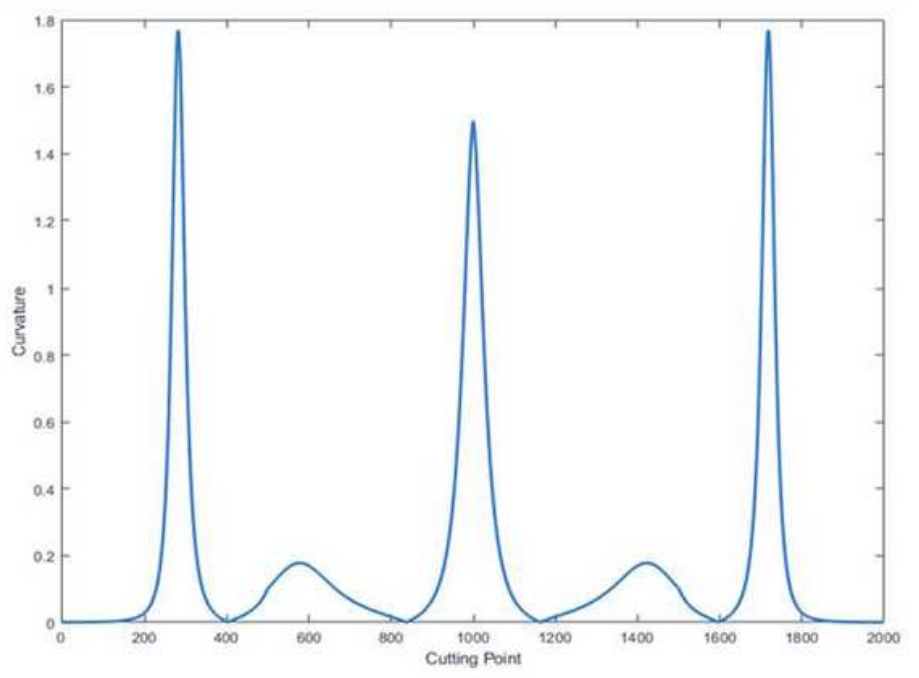

(a)

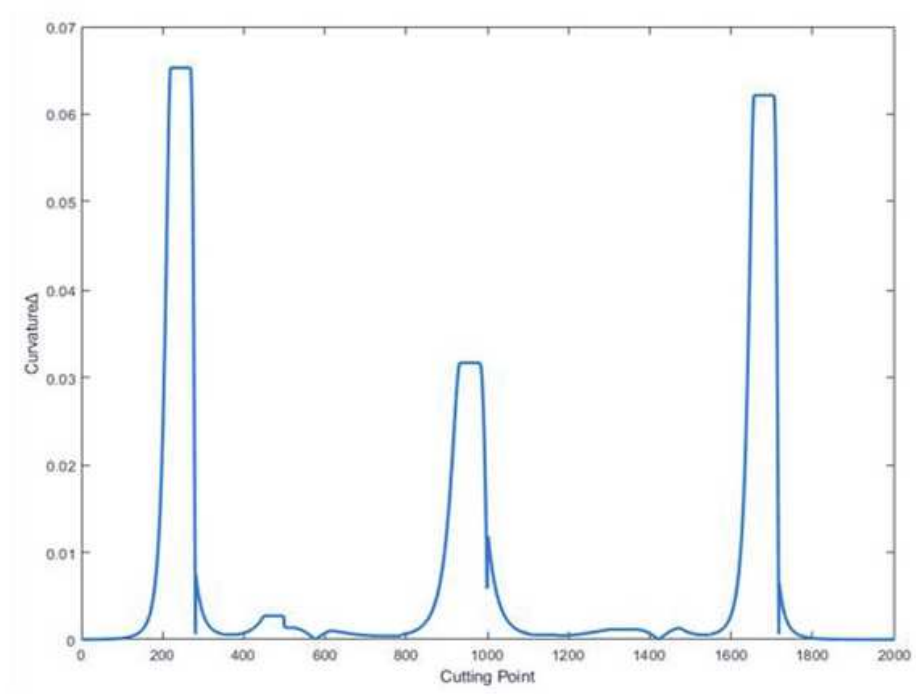

(b)

Figure 9

(a) Curvature and (b) curvature variation of trident shape 


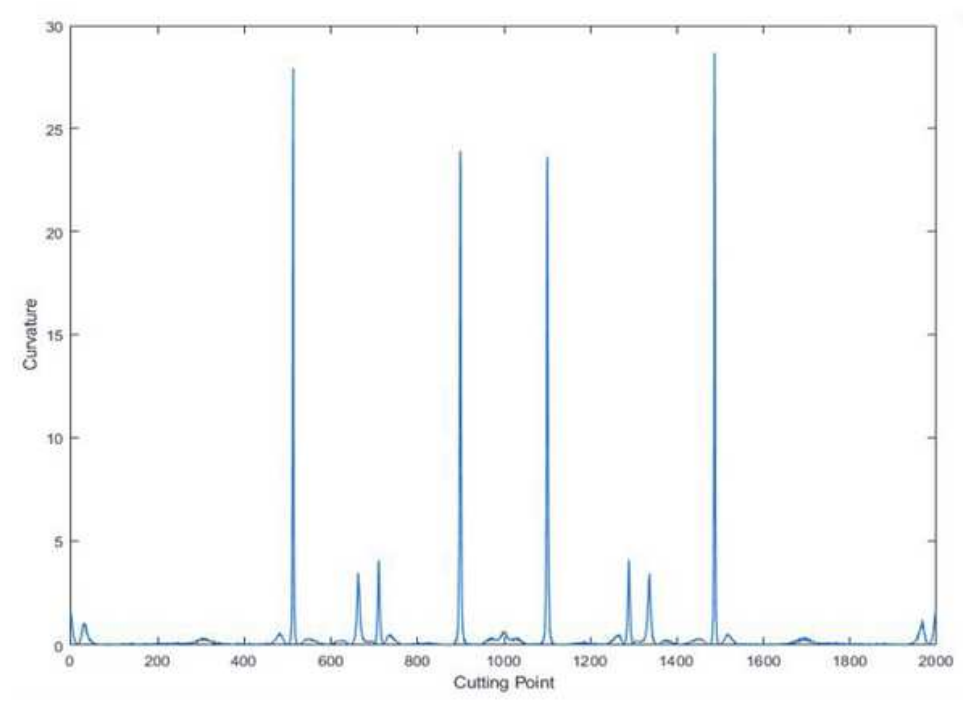

(a)

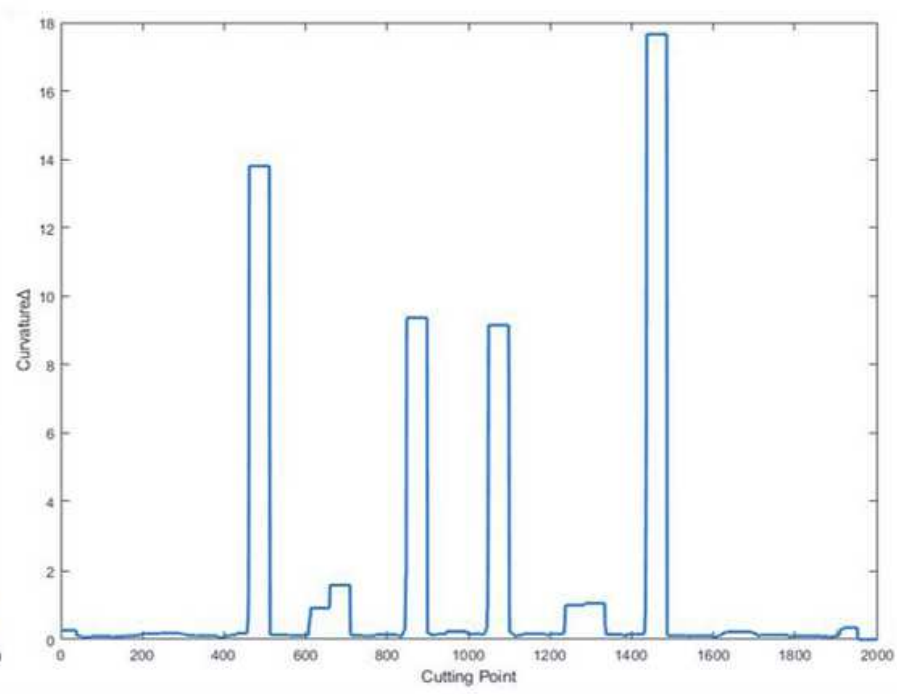

(b)

\section{Figure 10}

(a) Curvature and (b) curvature variation of butterfly shape

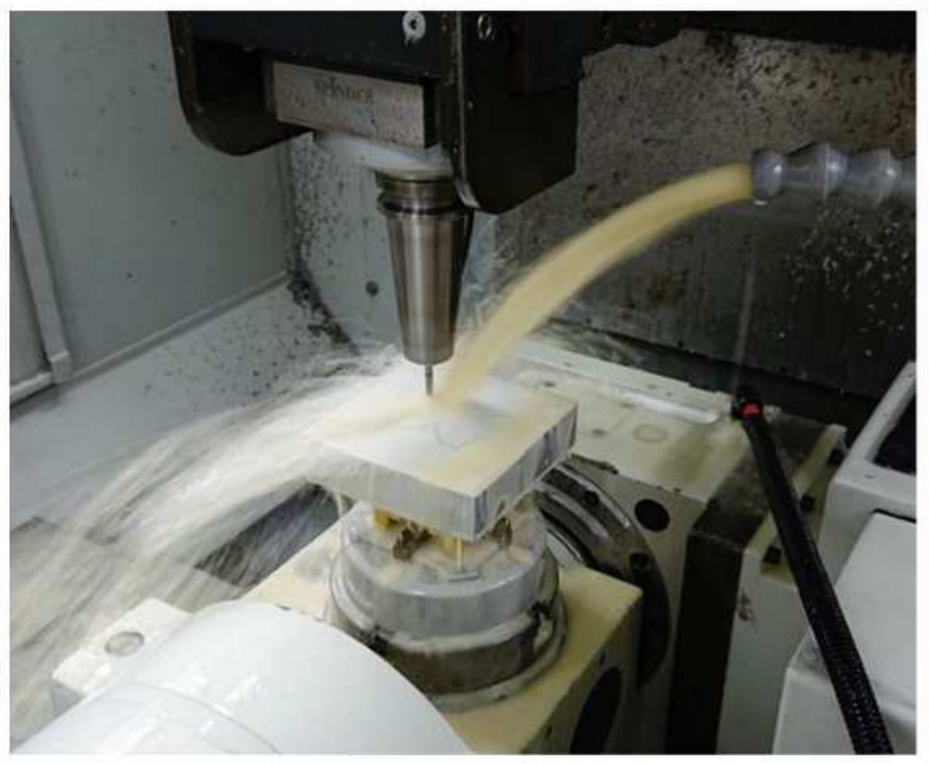

(a)

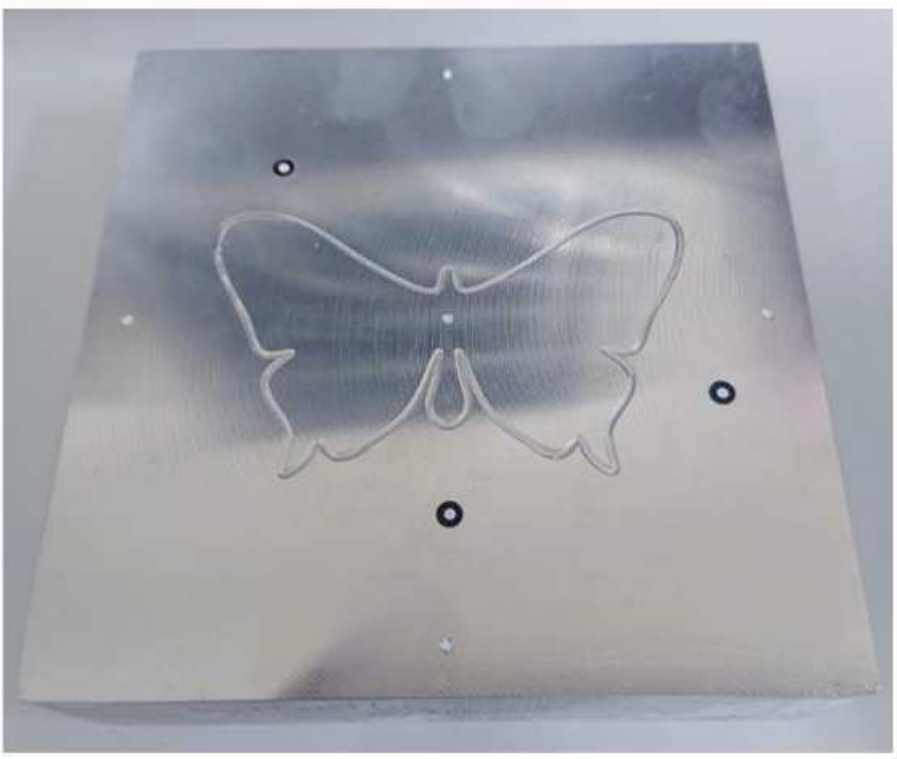

(b)

Figure 11

(a) Cutting of aluminum workpiece and (b) aluminum workpiece after cutting 


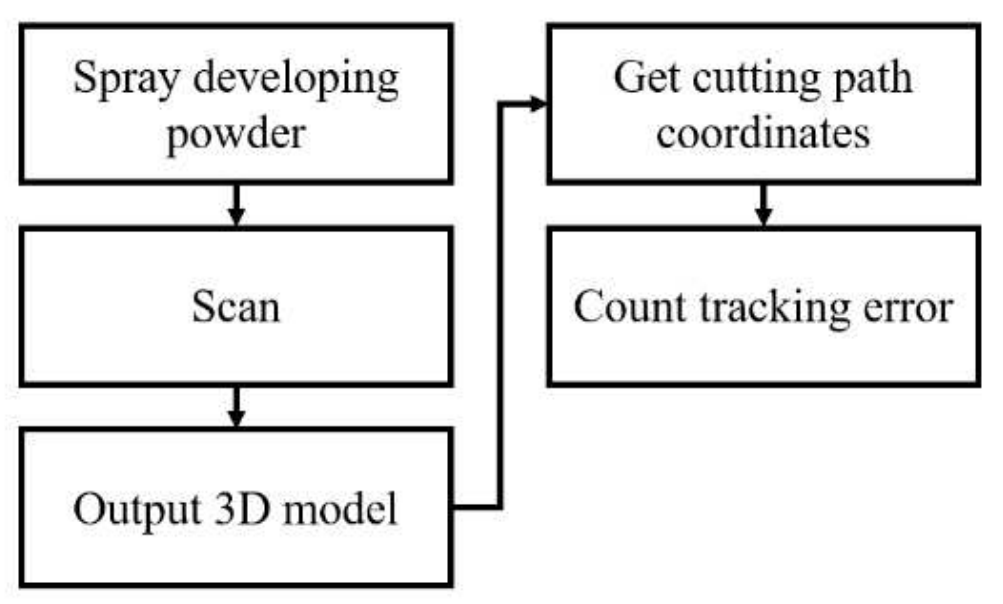

(a)

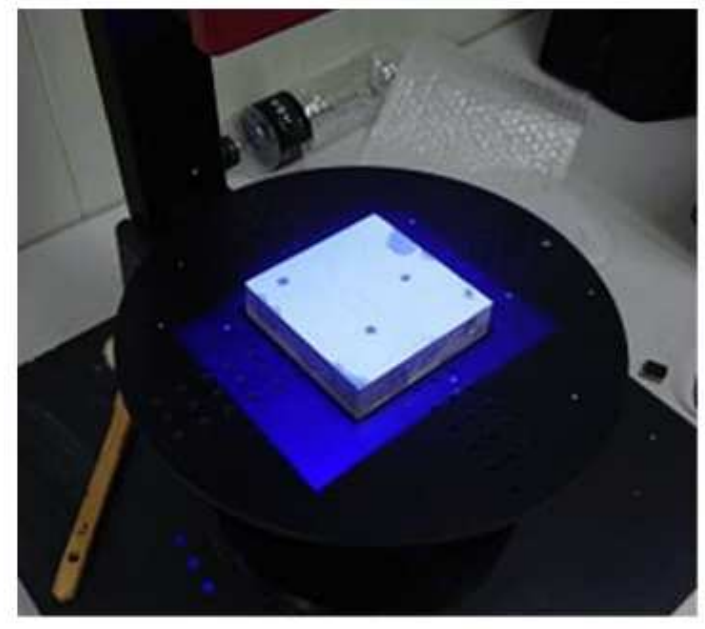

(c)

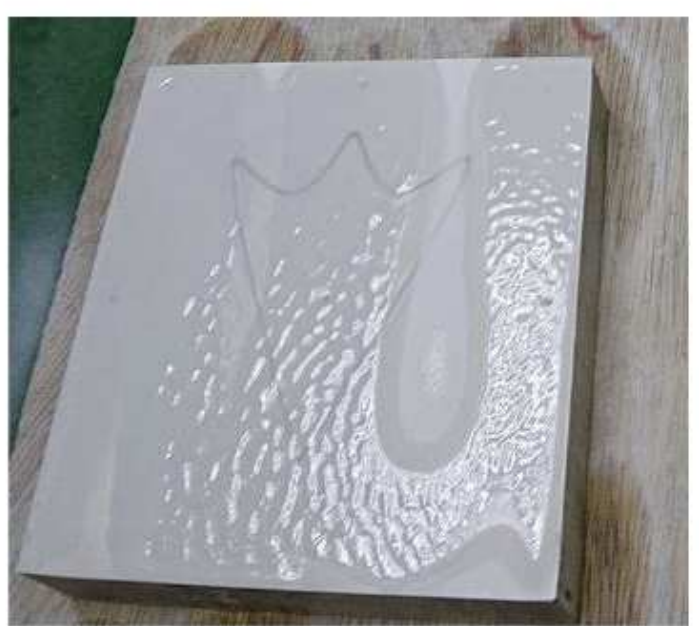

(b)

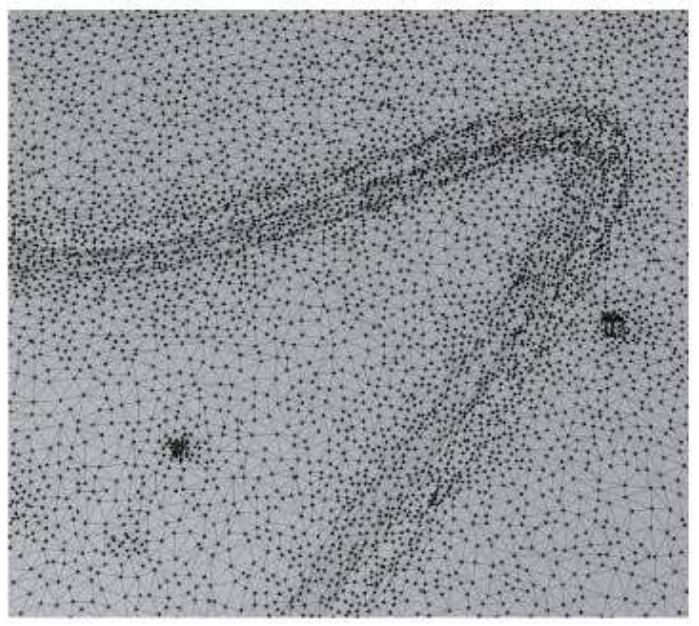

(d)

\section{Figure 12}

(a) Flowchart of optical 3D scanner measurement, (b) spraying of developing powder, (c) scanning using optical 3D scanner, and (d) 3D graphics after scanning aluminum workpieces 


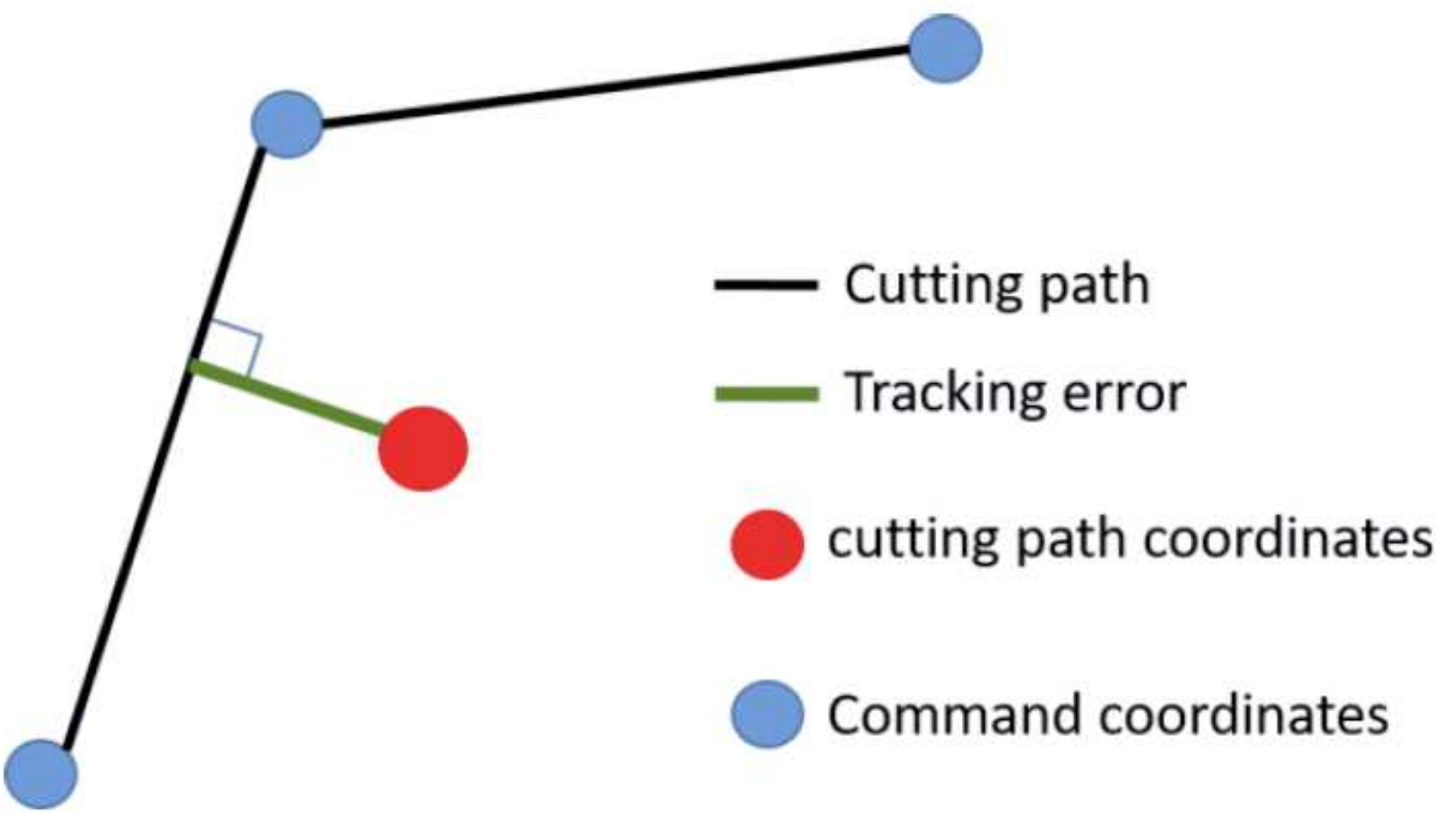

Figure 13

Cutting path error calculation.

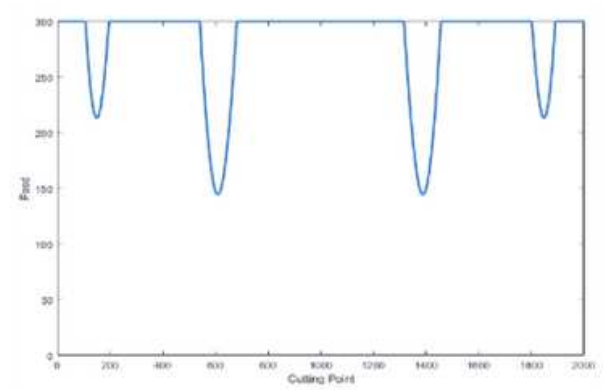

(a)

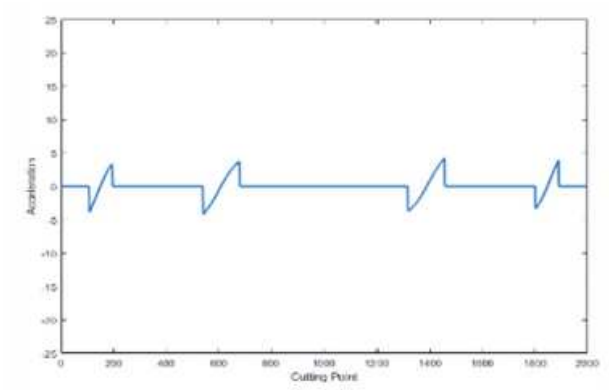

(b)

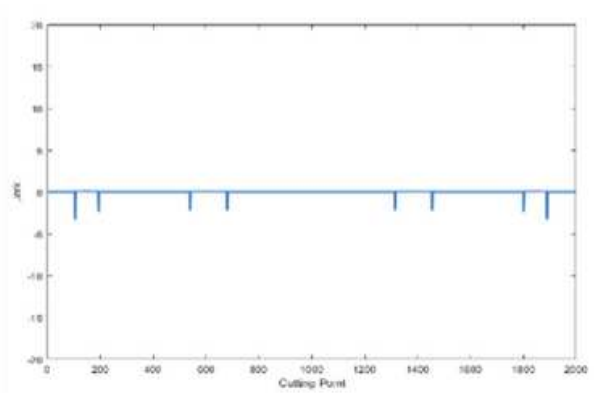

(c)

Figure 14

Cutting $\infty$ shape using method by Luan et al. [9]: (a) feedrate, (b) acceleration, and (c) jerk.

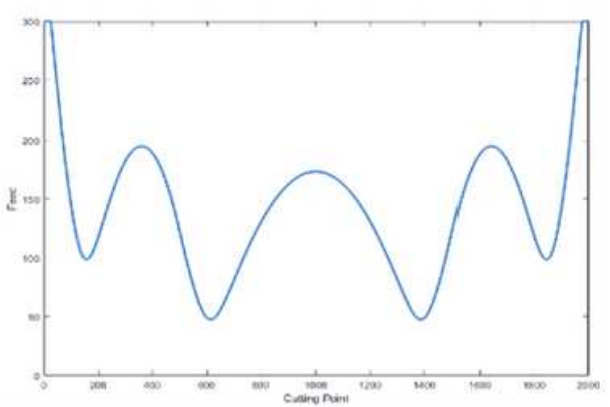

(a)

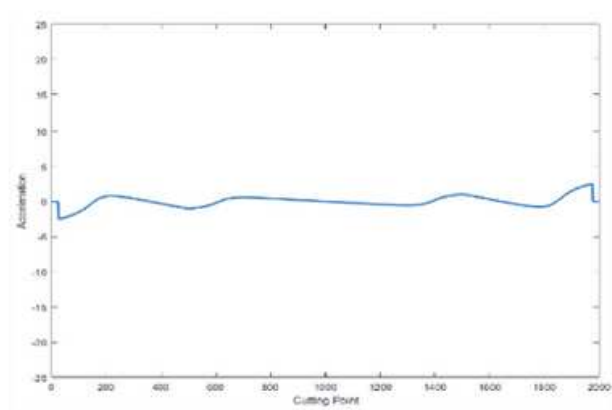

(b)

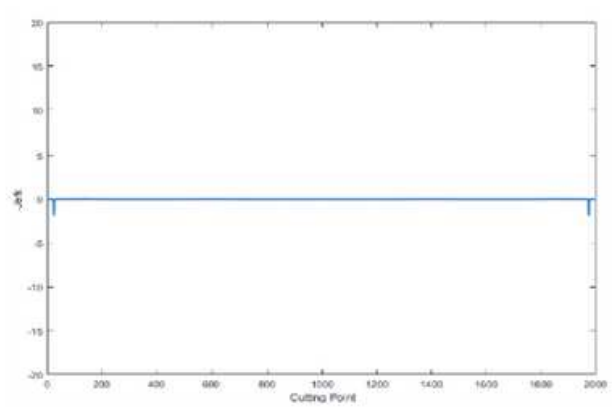

(c) 
Figure 15

Cutting $\infty$ shape using method by Yeh and Hsu [10]: (a) feedrate, (b) acceleration, and (c) jerk.

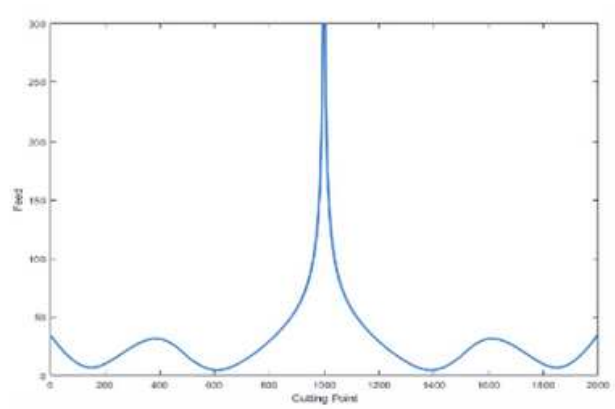

(a)

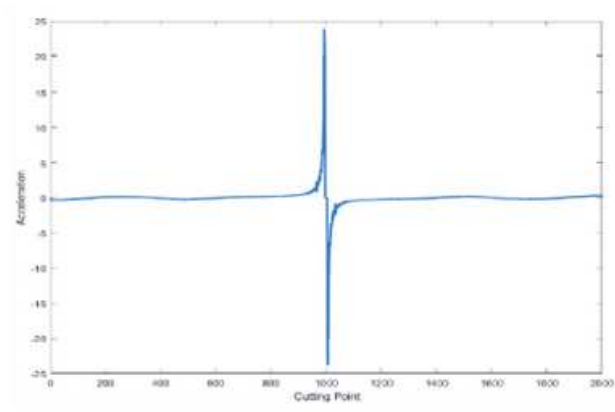

(b)

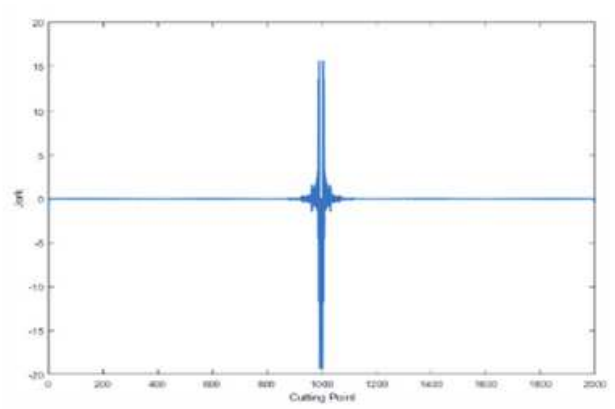

(c)

Figure 16

Cutting $\infty$ shape using method by Giannelli et al. [11]: (a) feedrate, (b) acceleration, and (c) jerk.

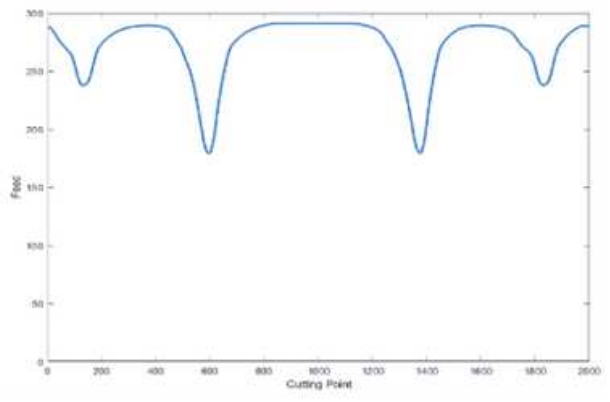

(a)

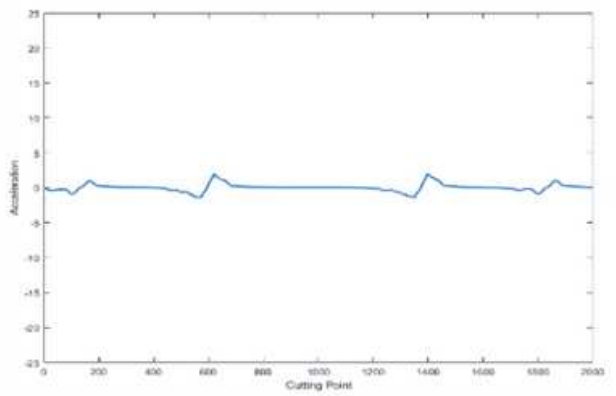

(b)

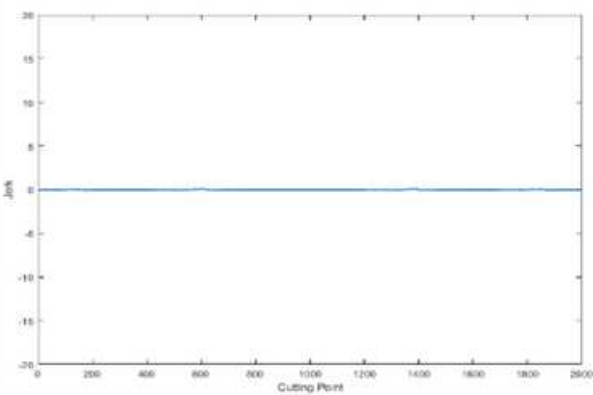

(c)

\section{Figure 17}

Cutting $\infty$ shape using our method: (a) feedrate, (b) acceleration, and (c) jerk.

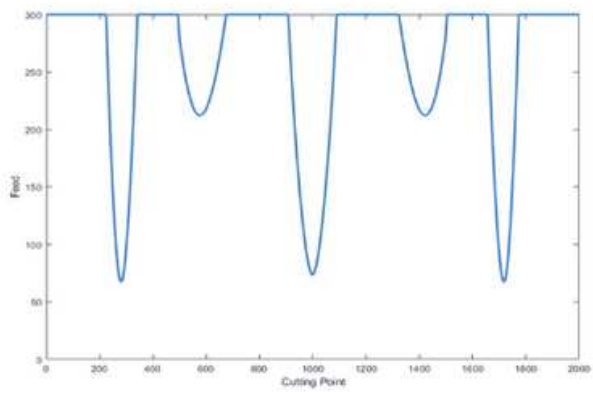

(a)

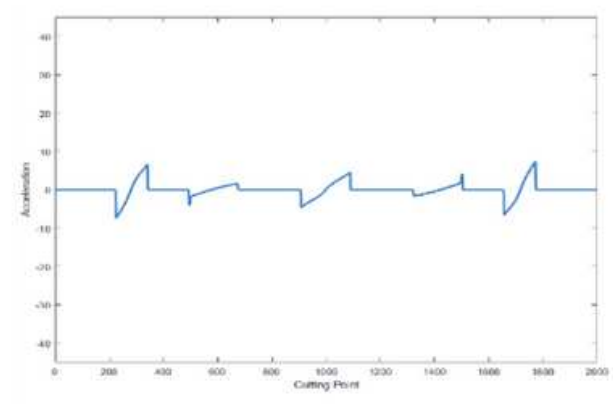

(b)

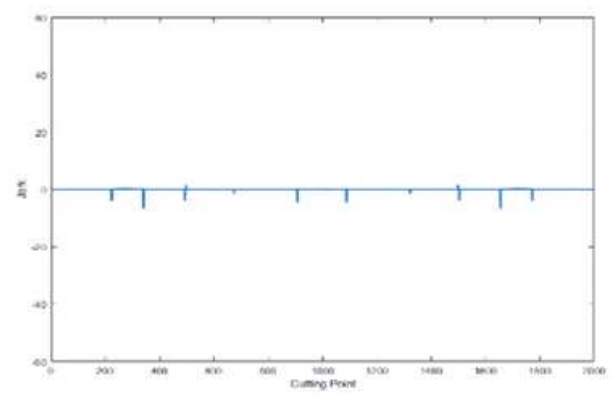

(c)

\section{Figure 18}

Cutting trident shape using method by Luan et al. [9]: (a) feedrate, (b) acceleration, and (c) jerk. 


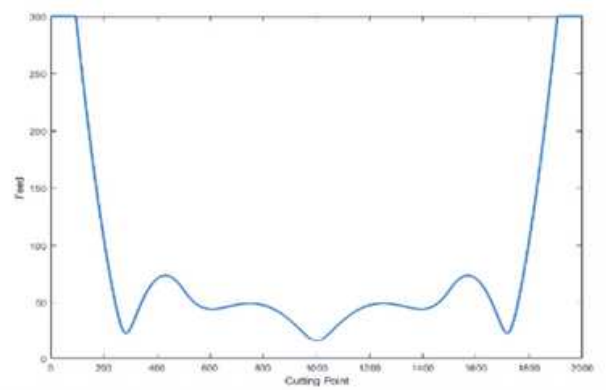

(a)

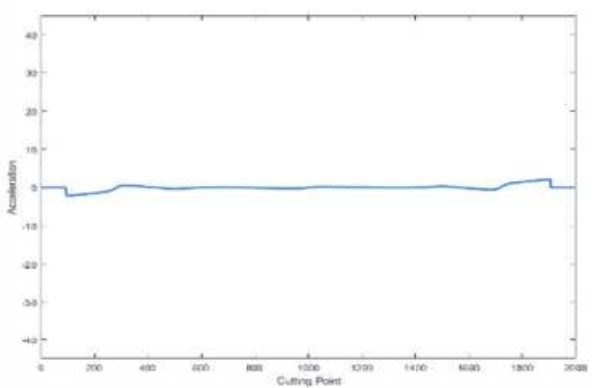

(b)

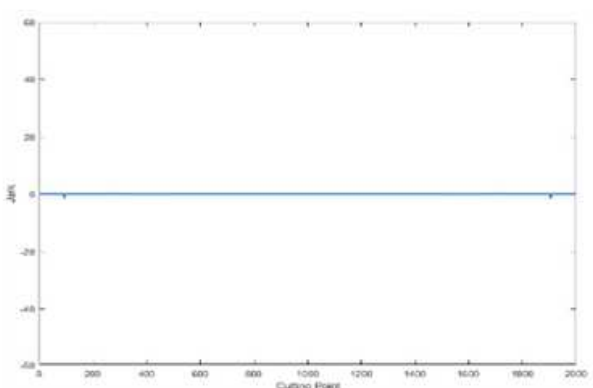

(c)

\section{Figure 19}

Cutting trident shape using method by Yeh and Hsu [10]: (a) feedrate, (b) acceleration, and (c) jerk.

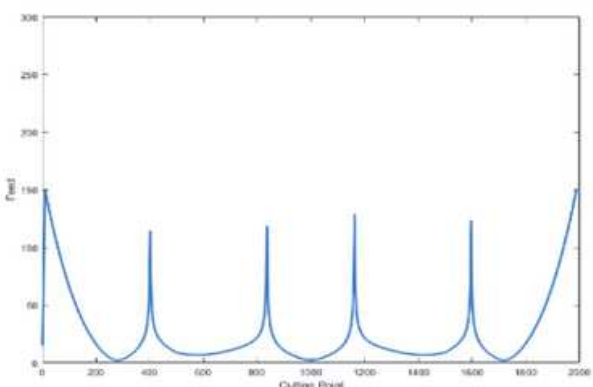

(a)

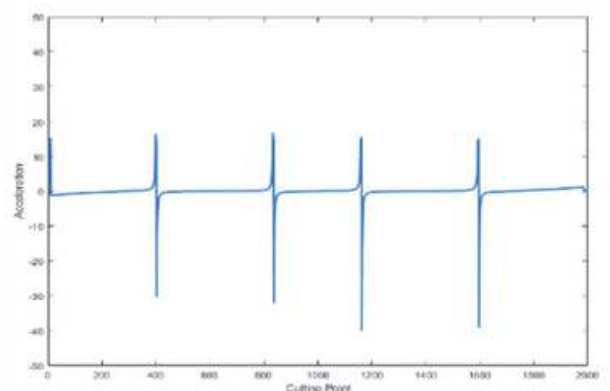

(b)

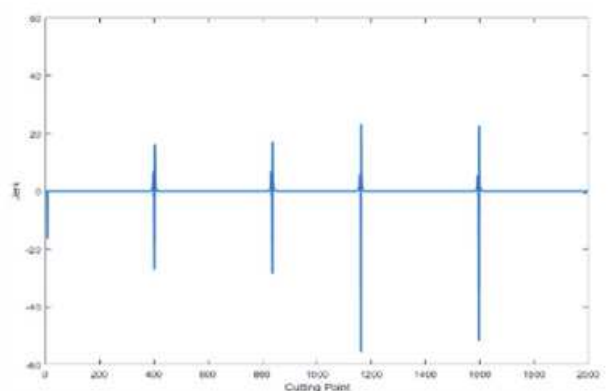

(c)

Figure 20

Cutting trident shape using method by Giannelli et al. [11]: (a) feedrate, (b) acceleration, and (c) jerk.

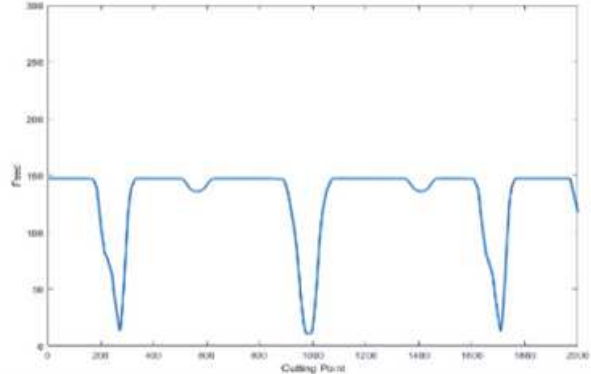

(a)

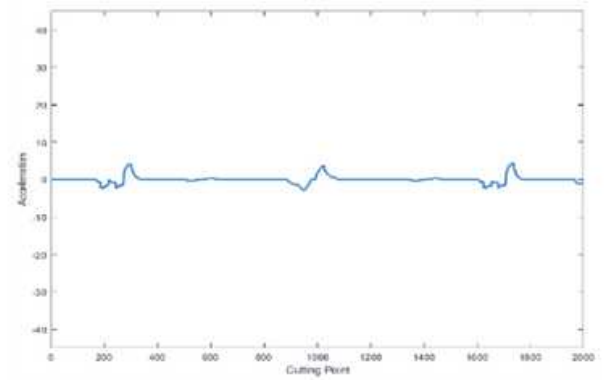

(b)

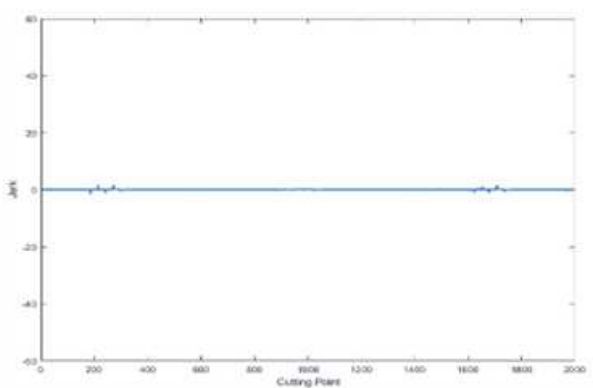

(c)

\section{Figure 21}

Cutting trident shape using our method with maximum feedrate of $150 \mathrm{~m} / \mathrm{min}$ : (a) feedrate, (b) acceleration, and (c) jerk. 


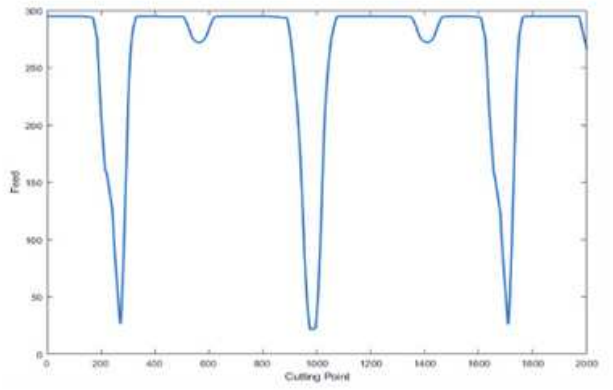

(a)

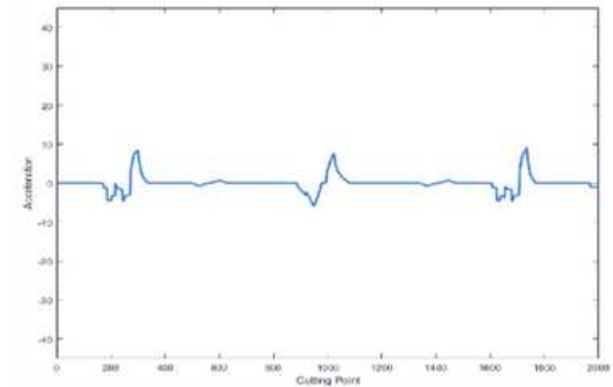

(b)

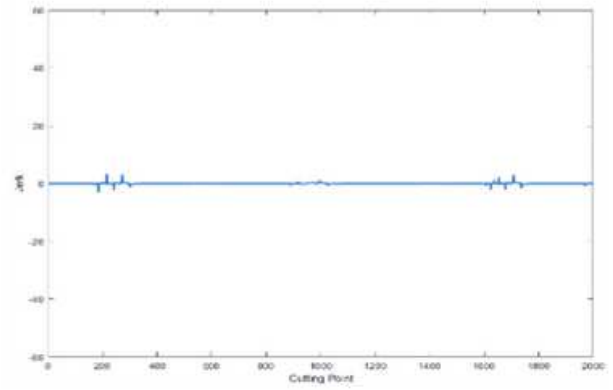

(c)

\section{Figure 22}

Cutting trident shape using our method with maximum feedrate of $300 \mathrm{~m} / \mathrm{min}$ : (a) feedrate, (b) acceleration, and (c) jerk.

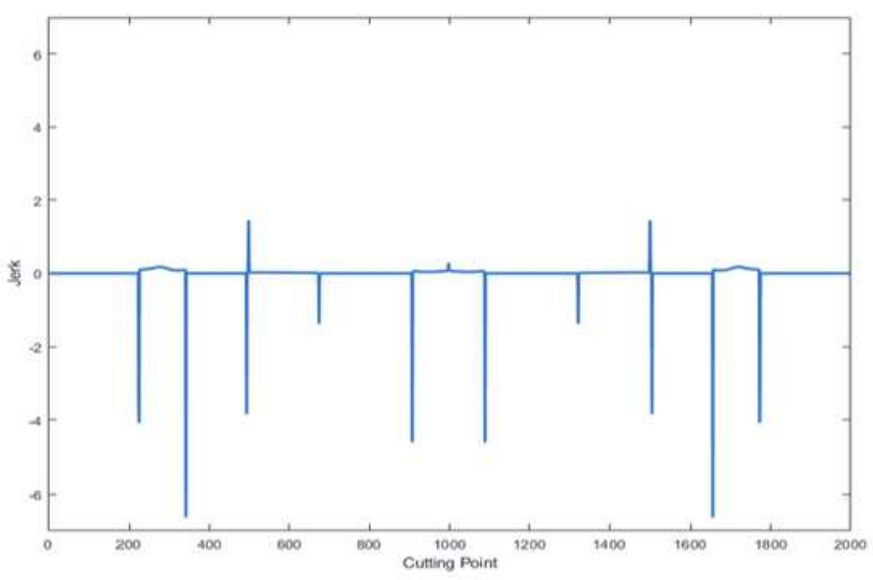

(a)

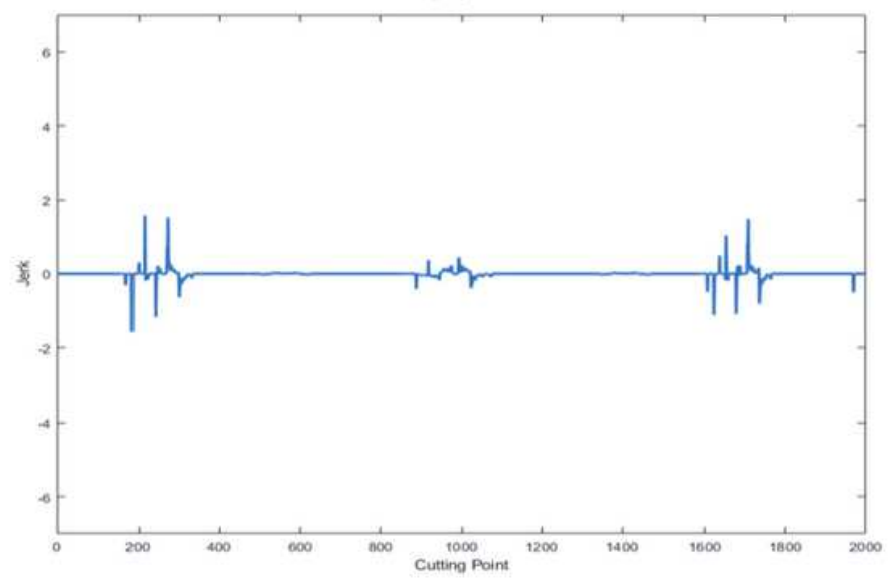

(c)

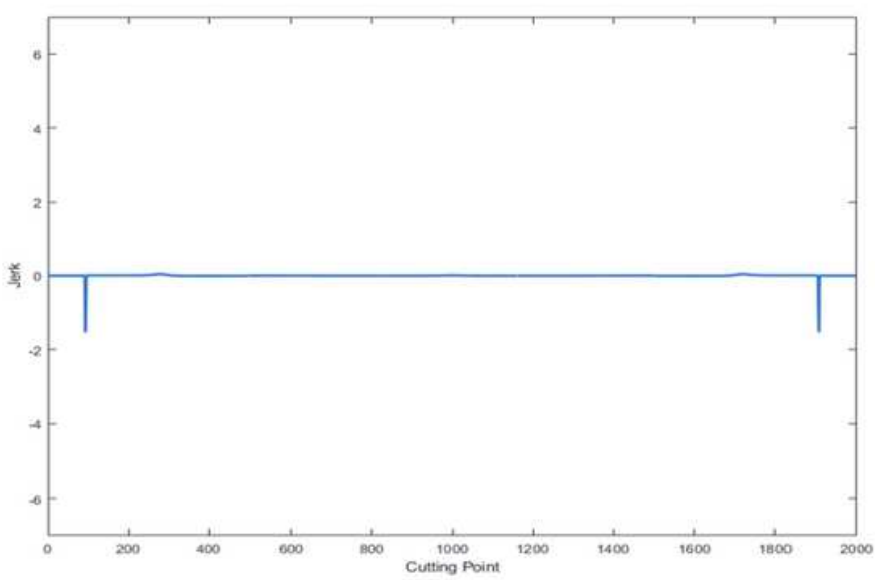

(b)

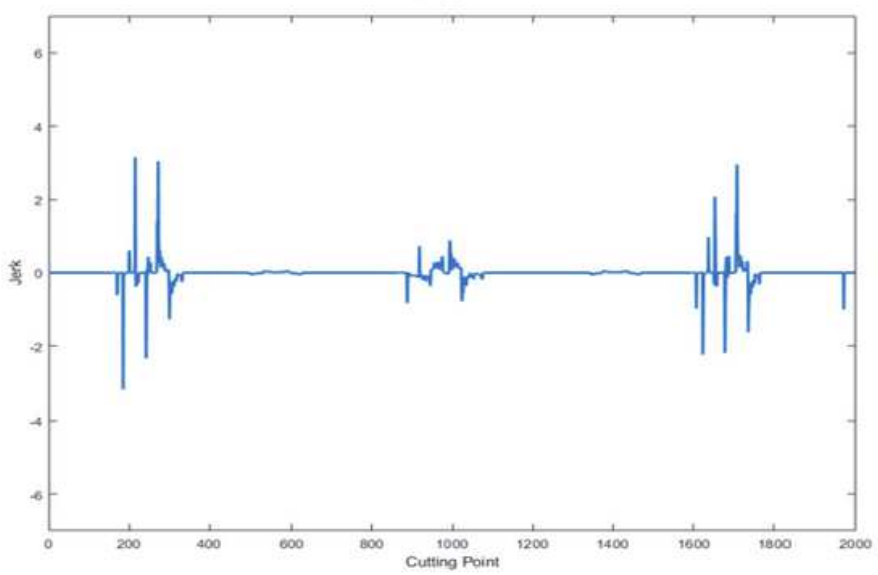

(d)

\section{Figure 23}

Jerk when cutting trident shape using (a) method by Luan et al. [9], (b) method by Yeh and Hsu [10], (c) our method with maximum feedrate of $150 \mathrm{~m} / \mathrm{min}$, and (d) our method with maximum feedrate of 300 $\mathrm{m} / \mathrm{min}$. 


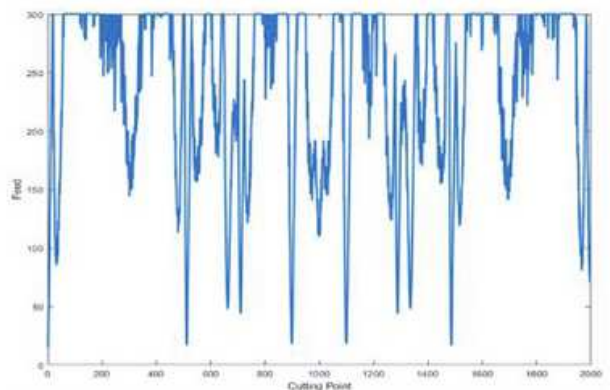

(a)

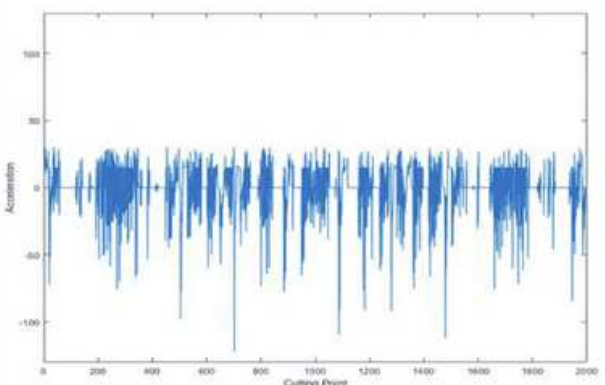

(b)

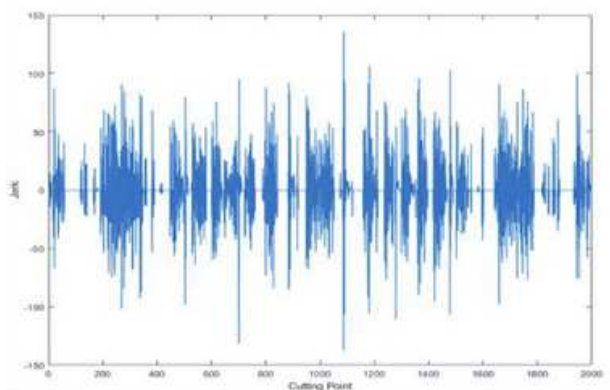

(c)

Figure 24

Cutting butterfly shape using method by Luan et al. [9]: (a) feedrate, (b) acceleration, and (c) jerk.

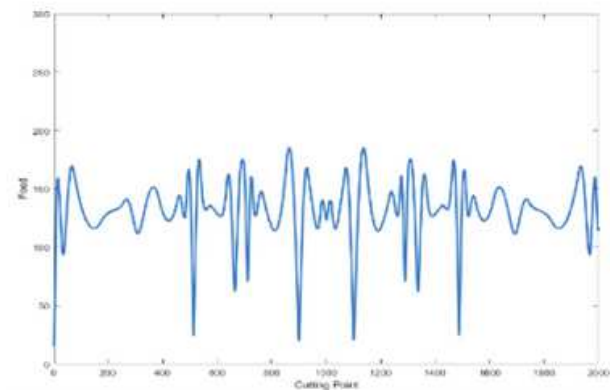

(a)

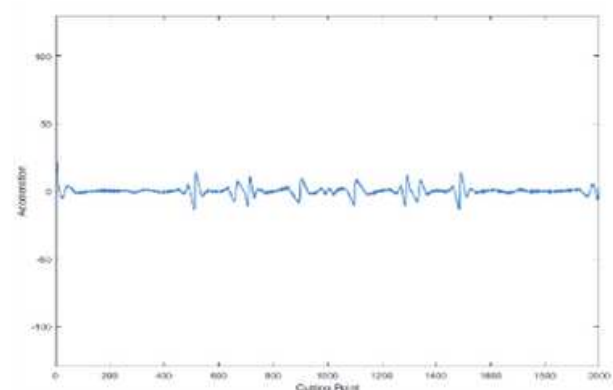

(b)

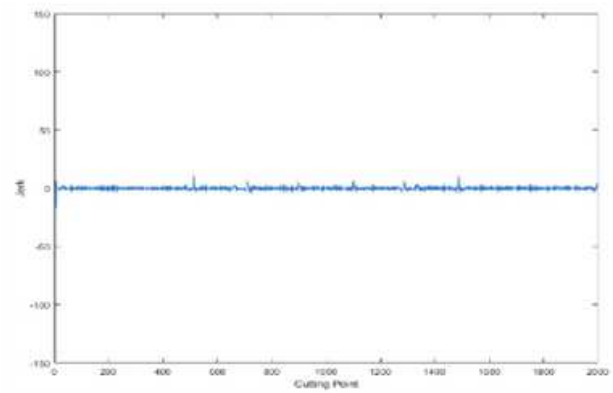

(c)

Figure 25

Cutting butterfly shape using method by Yeh and Hsu [10]: (a) feedrate, (b) acceleration, and (c) jerk.

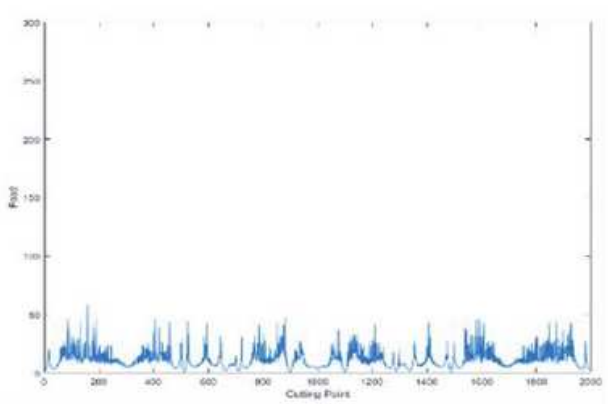

(a)

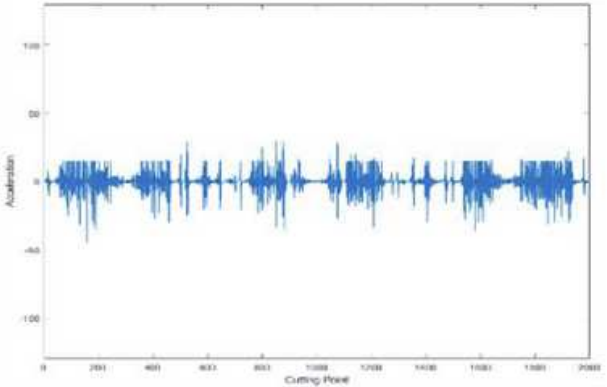

(b)

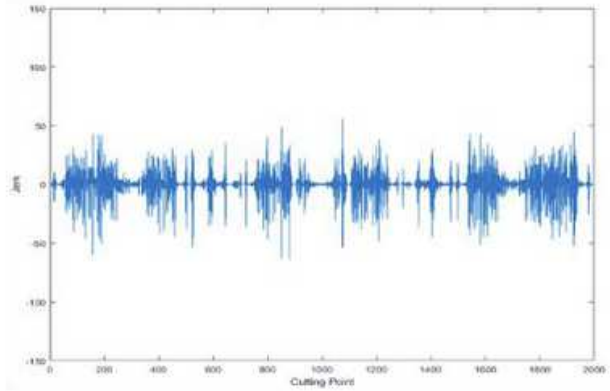

(c)

Figure 26

Cutting butterfly shape using method by Giannelli et al. [11]: (a) feedrate, (b) acceleration, and (c) jerk. 


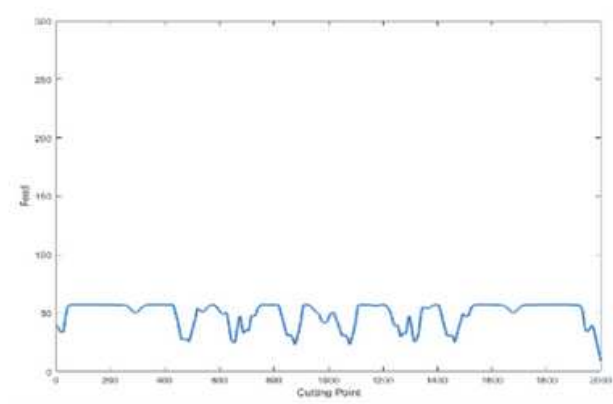

(a)

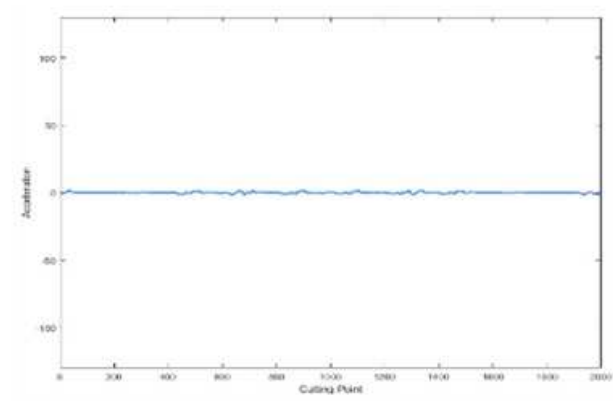

(b)

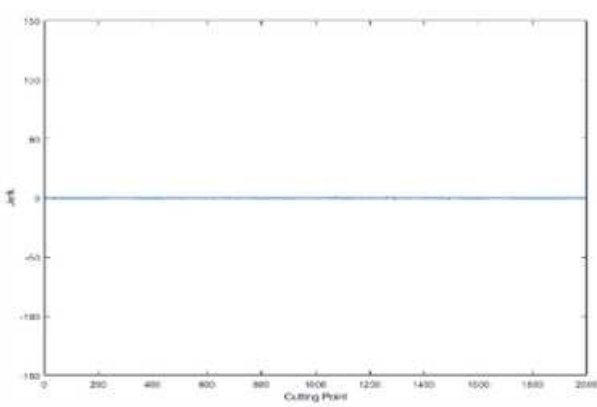

(c)

\section{Figure 27}

Cutting butterfly shape using our method with maximum feedrate of $58 \mathrm{~m} / \mathrm{min}$ : (a) feedrate, (b) acceleration, and (c) jerk.

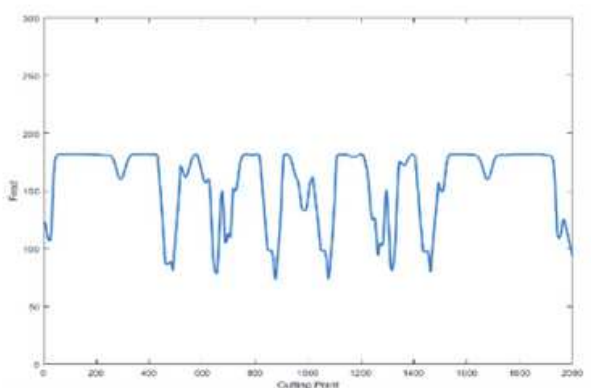

(a)

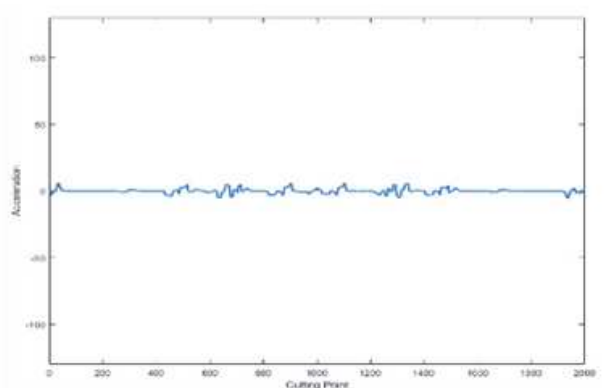

(b)

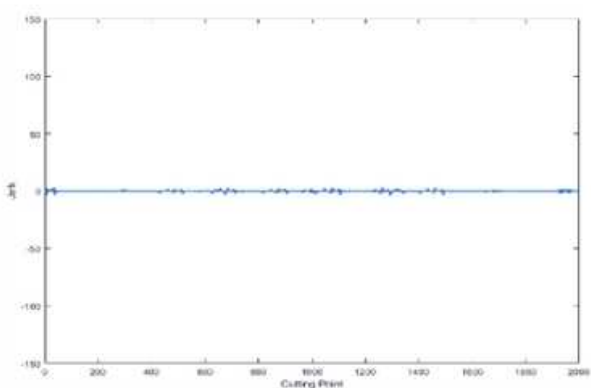

(c)

\section{Figure 28}

Cutting butterfly shape using our method with maximum feedrate of $185 \mathrm{~m} / \mathrm{min}$ : (a) feedrate, (b) acceleration, and (c) jerk.

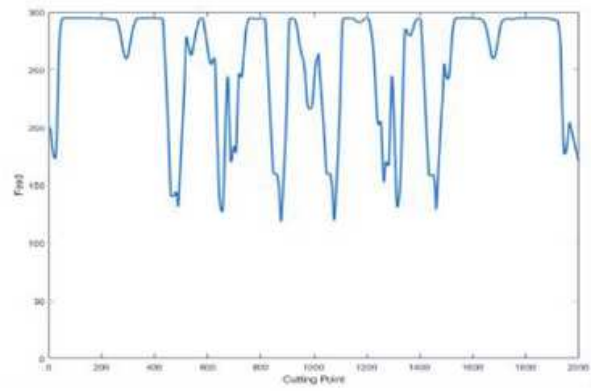

(a)

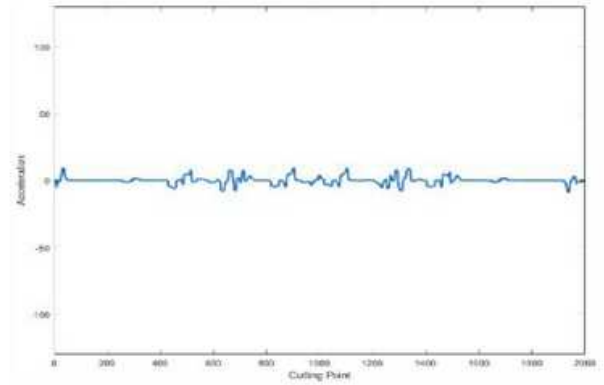

(b)

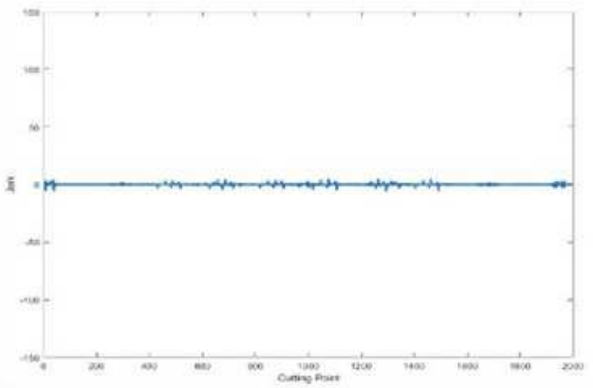

(c)

Figure 29

Cutting butterfly shaped using our method with maximum feedrate of $300 \mathrm{~m} / \mathrm{min}$ : (a) feedrate, (b) acceleration, and (c) jerk. 